\title{
Modeling of Cell Aggregation Dynamics Governed by Receptor-Ligand Binding Under Shear Flow
}

\author{
Changliang Fu, ${ }^{1,2,3}$ Chunfang Tong, ${ }^{1,2,3}$ Cheng Dong, ${ }^{4}$ and Mian Long ${ }^{1,2,3}$ \\ ${ }^{1}$ Key Laboratory of Microgravity, Institute of Mechanics, Chinese Academy of Sciences, Beijing 100190, People's Republic \\ of China; ${ }^{2}$ National Microgravity Laboratory, Institute of Mechanics, Chinese Academy of Sciences, Beijing, \\ People's Republic of China; ${ }^{3}$ Center of Biomechanics and Bioengineering, Institute of Mechanics, Chinese Academy \\ of Sciences, Beijing, People's Republic of China; and ${ }^{4}$ Department of Bioengineering, The Pennsylvania State University, \\ University Park, PA 16802, USA
}

(Received 14 February 2011; accepted 15 April 2011; published online 26 April 2011)

Associate Editor Edward Guo oversaw the review of this article.

\begin{abstract}
Shear-induced cell aggregation and disaggregation, governed by specific receptor-ligand binding, play important roles in many biological and biophysical processes. While a lot of studies have focused on elucidating the shear rate and shear stress dependence of cell aggregation, the majority of existing models based on population balance equation (PBE) has rarely dealt with cell aggregation dynamics upon intrinsic molecular kinetics. Here, a kinetic model was developed for further understanding cell aggregation and disaggregation in a linear shear flow. The novelty of the model is that a set of simple equations was constructed by coupling two-body collision theory with receptor-ligand binding kinetics. Two cases of study were employed to validate the model: one is for the homotypic aggregation dynamics of latex beads cross-linked by protein G-IgG binding, and the other is for the heterotypic aggregation dynamics of neutrophils-tumor cells governed by $\beta_{2}$-integrinligand interactions. It was found that the model fits the data well and the obtained kinetic parameters are consistent with the previous predictions and experimental measurements. Moreover, the decay factor defined biophysically to account for the chemokine- and shear-induced regulation of receptor and/or ligand expression and conformation was compared at molecular and cellular levels. Our results provided a universal framework to quantify the molecular kinetics of receptor-ligand binding in shear-induced cell aggregation dynamics.
\end{abstract}

Keywords-Two-dimensional kinetics, Cone-plate viscometer, Homotypic aggregation, Heterotypic aggregation, Bell model, Protein G-IgG bond, $\beta_{2}$-Integrin and ICAM-1 bond.

\footnotetext{
Address correspondence to Mian Long, Key Laboratory of Microgravity, Institute of Mechanics, Chinese Academy of Sciences, Beijing 100190, People's Republic of China. Electronic mail: mlong@ imech.ac.cn
}

\section{LIST OF SYMBOLS}

\begin{tabular}{|c|c|}
\hline$a$ & Bond interaction range $(\mathrm{nm})$ \\
\hline$A_{\mathrm{c}}$ & $\begin{array}{l}\text { Contact area between two contact } \\
\text { spheres }\left(\mu \mathrm{m}^{2}\right)\end{array}$ \\
\hline $\begin{array}{l}A_{\mathrm{c}} m_{\mathrm{r}} m_{\mathrm{l}} k_{\mathrm{f}} \\
\left(A_{\mathrm{c}} m_{\mathrm{r}} m_{\mathrm{l}} k_{\mathrm{f}}\right)^{0}\end{array}$ & $\begin{array}{l}\text { Effective forward rate, value at the } \\
\text { moment immediately after PMN } \\
\text { stimulation }\left(\mathrm{s}^{-1}\right)\end{array}$ \\
\hline$C ; C_{1}, C_{10}$ & Concentration of sphere; value of \\
\hline$C_{2}, C_{20}$ & $\begin{array}{l}\text { sphere } 1 \text {, initial value; value of } \\
\text { sphere } 2 \text {, initial value }\left(\mathrm{m}^{-3}\right)\end{array}$ \\
\hline$C_{\mathrm{f}},\left\langle C_{\mathrm{f}}\right\rangle$ & $\begin{array}{l}\text { Angle factor }\left(=\left(\sin ^{2} \theta_{1} \sin 2 \phi_{1}\right)_{\max }\right) \text {, } \\
\text { mean value }\end{array}$ \\
\hline$C_{\mathrm{O}}$ & Orbit constant \\
\hline$E, E_{0}$ & $\begin{array}{l}\text { Adhesion efficiency, value at the } \\
\text { moment immediately after PMN } \\
\text { stimulation }\end{array}$ \\
\hline$f_{\mathrm{c}}, f_{\mathrm{c} 0}$ & $\begin{array}{l}\text { Two-body collision frequency per } \\
\text { unit volume per sphere } 2 \text {, initial } \\
\text { value }\left(\mathrm{s}^{-1}\right)\end{array}$ \\
\hline$F ; F_{\mathrm{N}}, F_{\mathrm{N}, \max }$ & Applied force; normal force, \\
\hline$F_{\mathrm{S}}, F_{\mathrm{S}, \max }$ & $\begin{array}{l}\text { maximum value; shear force, } \\
\text { maximum value }(\mathrm{pN})\end{array}$ \\
\hline$G$ & Shear rate $\left(\mathrm{s}^{-1}\right)$ \\
\hline$k_{\mathrm{B}}$ & $\begin{array}{l}\text { Boltzmann constant } \\
\left(=1.38 \times 10^{-23} \mathrm{~N} \mathrm{~m} \mathrm{~K}^{-1}\right)\end{array}$ \\
\hline$k_{\mathrm{f}}, k_{\mathrm{f}}^{\mathrm{L}}, k_{\mathrm{f}}^{\mathrm{H}}$ & $\begin{array}{l}\text { Forward rate, values from low and } \\
\text { high shear rate, respectively } \\
\left(\mu \mathrm{m}^{2} \mathrm{~s}^{-1}\right)\end{array}$ \\
\hline$k_{\mathrm{r}}, k_{\mathrm{r}}^{(n)}, k_{\mathrm{r}}^{0}$ & $\begin{array}{l}\text { Reverse rate, value for dissociation } \\
\text { of } n \text {-th bond, value at zero force } \\
\left(\mathrm{s}^{-1}\right)\end{array}$ \\
\hline$M$ & Number of data points \\
\hline$n,\langle n\rangle$ & Number of bonds, mean value \\
\hline$N$ & $\begin{array}{l}\text { Maximum number of bonds } \\
\text { possibly to link the doublet }\end{array}$ \\
\hline
\end{tabular}




\begin{tabular}{|c|c|}
\hline$p_{n}, p_{\mathrm{c} n}$ & $\begin{array}{l}\text { Probability of having } n \text { bonds, } \\
\text { probability of having } n \text { bonds at the } \\
\text { end moment of two-body collision } \\
(n=0,1,2 \ldots)\end{array}$ \\
\hline$P_{\mathrm{a}}, P_{\mathrm{a}}^{30}$ & $\begin{array}{l}\text { Probability of adhesion, equilibrium } \\
\text { aggregation percentage at } 30 \mathrm{~min} \text { for } \\
\text { latex bead homotypic aggregation }\end{array}$ \\
\hline$P_{\mathrm{b}}$ & Fraction of doublet break-up \\
\hline$r, r_{1}, r_{2}$ & $\begin{array}{l}\text { Radius of sphere, value of sphere } 1 \text {, } \\
\text { value of sphere } 2(\mu \mathrm{m})\end{array}$ \\
\hline$r_{\mathrm{e}}$ & Equivalent axis ratio of doublet \\
\hline$t$ & Arbitrary time (s) \\
\hline$T$ & Period of doublet rotation (s) \\
\hline$T_{\mathrm{K}}$ & Absolute temperature $(\mathrm{K})$ \\
\hline$u_{1}, u_{2}, u_{3}$ & $\begin{array}{l}\text { Fluid velocity, } u_{1}=u_{2}=0 \text { and } \\
u_{3}=G X_{2}\left(\mu \mathrm{m} \mathrm{s}^{-1}\right)\end{array}$ \\
\hline$X_{1}, X_{2}, X_{3}$ & Cartesian coordinates $(\mu \mathrm{m})$ \\
\hline$y_{i}, y\left(x_{i}\right)$ & $\begin{array}{l}\text { Measurement and prediction values } \\
\text { at } x_{i}\end{array}$ \\
\hline$\alpha_{\mathrm{c}}, \alpha_{\mathrm{m}}$ & $\begin{array}{l}\text { Decay factors at cellular and } \\
\text { molecular level, respectively }\left(\mathrm{s}^{-1}\right)\end{array}$ \\
\hline$\alpha_{\mathrm{N}}, \alpha_{\mathrm{S}}$ & $\begin{array}{l}\text { Normal and shear force coefficients, } \\
\text { respectively }\end{array}$ \\
\hline$\varepsilon$ & $\begin{array}{l}\text { Two-body collision capture } \\
\text { efficiency }\end{array}$ \\
\hline$\eta$ & $\begin{array}{l}\text { Medium viscosity } \\
\left(\mathrm{cP},=\mathrm{mPa} \mathrm{s}=10^{-3} \mathrm{~N} \mathrm{~s} \mathrm{~m}^{-2}\right)\end{array}$ \\
\hline$\theta_{1}, \phi_{1}$ & $\begin{array}{l}\text { Polar and azimuthal angles of } \\
\text { doublet major axis with respect to } X_{1}\end{array}$ \\
\hline$\theta_{2}$ & $\begin{array}{l}\text { Polar angle of doublet axis respect } \\
\text { to } X_{2}\end{array}$ \\
\hline$\phi_{1}^{0}$ & $\begin{array}{l}\text { Contact angle of two colliding } \\
\text { spheres }\end{array}$ \\
\hline$\sigma_{i}$ & Standard deviation \\
\hline$\tau, \bar{\tau}$ & $\begin{array}{l}\text { Two-body collision duration, } \\
\text { mean value (s) }\end{array}$ \\
\hline$\chi^{2}$ & Chi-square statistic \\
\hline
\end{tabular}

\section{INTRODUCTION}

Shear-induced aggregation and disaggregation of interacting cells/beads are fundamental to many significant events in biology, immunology, crystallization, and colloid and polymer science. In human circulation, blood cells collide with each other under shear flow and cell aggregation mediated by underlying receptorligand pairs frequently occurs under various physiological and pathological conditions. For example, platelet activation and homotypic aggregation induced by high shear stress or by chemical agonists (e.g., ADP, collagen, or thrombin) are involved in the pathogenesis of many diseases such as the development of atherosclerosis and accompanying thrombosis. ${ }^{8}$ Aggregation between platelets and neutrophils (PMNs) is relevant to the progression of thrombosis ${ }^{36}$ acute myocardial infarction, ${ }^{34}$ or unstable angina. ${ }^{35}$ Tumor cells also interact with platelets or leukocytes in blood flow to form emboli ${ }^{6,15,25,38}$ and facilitate tumor metastasis between neutrophil-melanoma cell, ${ }^{23,24,43,51}$ neutrophil-colon carcinoma cell, ${ }^{17,18}$ or tumor-platelet. ${ }^{16,28}$ Moreover, the aggregation between ligand-conjugated beads and blood cells or circulating tumor cells is crucial to drug delivery. Evidently, the dynamics of cell/bead aggregation under shear flow are required to quantify the aforementioned processes.

Homotypic or heterotypic aggregation of cells/ beads has been studied extensively using annular, tubular or parallel plate flow chambers, ${ }^{20}$ flow cytometry test tube with a small magnetic stir bar, ${ }^{40,54}$ or cone-plate viscometer. ${ }^{19}$ Among these approaches, the cone-plate viscometer consisting of a stationary plate beneath a rotating cone with a low angle $\left(<2^{\circ}\right)$ offers a uniform shear field (Couette flow) to the entire sample and is extensively applied in the study of shearinduced cell aggregation. ${ }^{19}$ The cone-plate viscometry assay was later combined with a two-color flow cytometry technique ${ }^{32,47}$ to elucidate the cellular and molecular mechanisms of blood cell aggregation. For example, a series of reports on shear-induced aggregation between neutrophils and ICAM-1 (intercellular adhesive molecule-1)-transfected cells revealed the cooperative and sequential roles of $\beta_{2}$-integrin in initial capture of neutrophils by $\alpha_{\mathrm{L}} \beta_{2}$ and following stabilization by $\alpha_{\mathrm{M}} \beta_{2}$ under chemotactic stimulation. ${ }^{10,31}$ Moreover, theoretical models based on population balance equation $(\mathrm{PBE})^{44}$ have been developed to estimate the size distribution of cell aggregates and predict the aggregation and disaggregation dynamics in a uniform shear field for the homotypic aggregation of human blood platelets, ${ }^{12-14}$ neutrophils, ${ }^{32}$ as well as for the heterotypic aggregation of platelets and neutrophils $^{22}$ or platelets and tumor cells. ${ }^{28}$ While these experimental and theoretical studies provided a better understanding in cell aggregation under distinct mechanical and chemotactic conditions, it is still hard to correlate the predicted aggregation dynamics at cellular level with the intrinsic molecular kinetics of underlying interacting molecules.

Cell aggregation is usually governed by two-dimensional (2D) kinetics of interacting molecules anchored on two opposed cell surfaces. ${ }^{24,52}$ In those pioneering work, a deterministic kinetic model was proposed, by setting a critical number of bonds to support stable formation of cell aggregates, to predict the collision efficiency and reverse rate of GPIIb/IIIa-fibrinogen binding for platelet aggregation, ${ }^{45}$ or $\beta_{2}$-integrinICAM-3 and L-selectin-PSGL-1 (P-selectin glycoprotein ligand 1) binding for neutrophil aggregation. ${ }^{46}$ 
Recent evidence indicated that 2D receptor-ligand binding mediated by a small number of bonds is no longer a deterministic but a stochastic process. ${ }^{5,7,53}$ To extract the molecular kinetic parameters from the time-dependent cell aggregation and disaggregation, we previously developed a probabilistic kinetic model to predict shear-induced doublet formations and breakages of red blood cells and of latex beads crossed-linked by antigen-antibody bonds. ${ }^{27}$ An assumption, where a doublet breakage was neglected at low shear rate and/or a doublet formation was ignored at high shear rate, was applied to simplify the process when estimating the intrinsic forward and reverse rates. ${ }^{27}$ However, these simplifications confined the application of the model. In this study, we further developed a universal framework by introducing the transition probabilities of zero-bond to $n \quad(n \geq 1)$ bonds based on Smoluchowski two-body collision theory ${ }^{44}$ and a well-developed probabilistic model of small system kinetics. ${ }^{5} \mathrm{~A}$ set of master equations were formulated following McQuarrie's theorem ${ }^{29}$ and then applied to quantify the cell aggregation dynamics and the molecular binding kinetics in different cases of homotypic and heterotypic aggregations.

\section{THEORETICAL MODELING}

We considered two unequal-sized cells (or beads) with radii $r_{1}$ and $r_{2}\left(r_{1}>r_{2}\right)$ that were assumed to behave as rigid spheres. The cells were evenly distributed in a uniform shear flow with initial concentrations $C_{10}$ and $C_{20}$, respectively. Two-body collision and hydrodynamic interactions are described, respectively, in the Cartesian and spherical-polar coordinates (Fig. 1a).

\section{Two-Body Collision of Unequal-Sized Cells in Shear Flow}

Cell collision occurs in a shear field due to the velocity gradient. Based on Smoluchowski two-body collision theory, ${ }^{44}$ the total number of collisions depends on cell concentrations, applied shear rate, and cell radii. In the case of two unequal-sized cells presenting at a shear rate $G$, the heterotypic collision frequency per unit volume was given by $4\left(r_{1}+r_{2}\right)^{3} G C_{1} C_{2} / 3$, where $C_{1}$ and $C_{2}$ are instantaneous cell concentrations in suspension. By dividing the cell concentration $C_{2}$, the two-body collision frequency per unit volume per cell 2 would be,

$$
f_{\mathrm{c}}=4\left(r_{1}+r_{2}\right)^{3} G C_{1} / 3 .
$$

The two-body collision brings the cells into contact and hence provides the opportunities for the surface

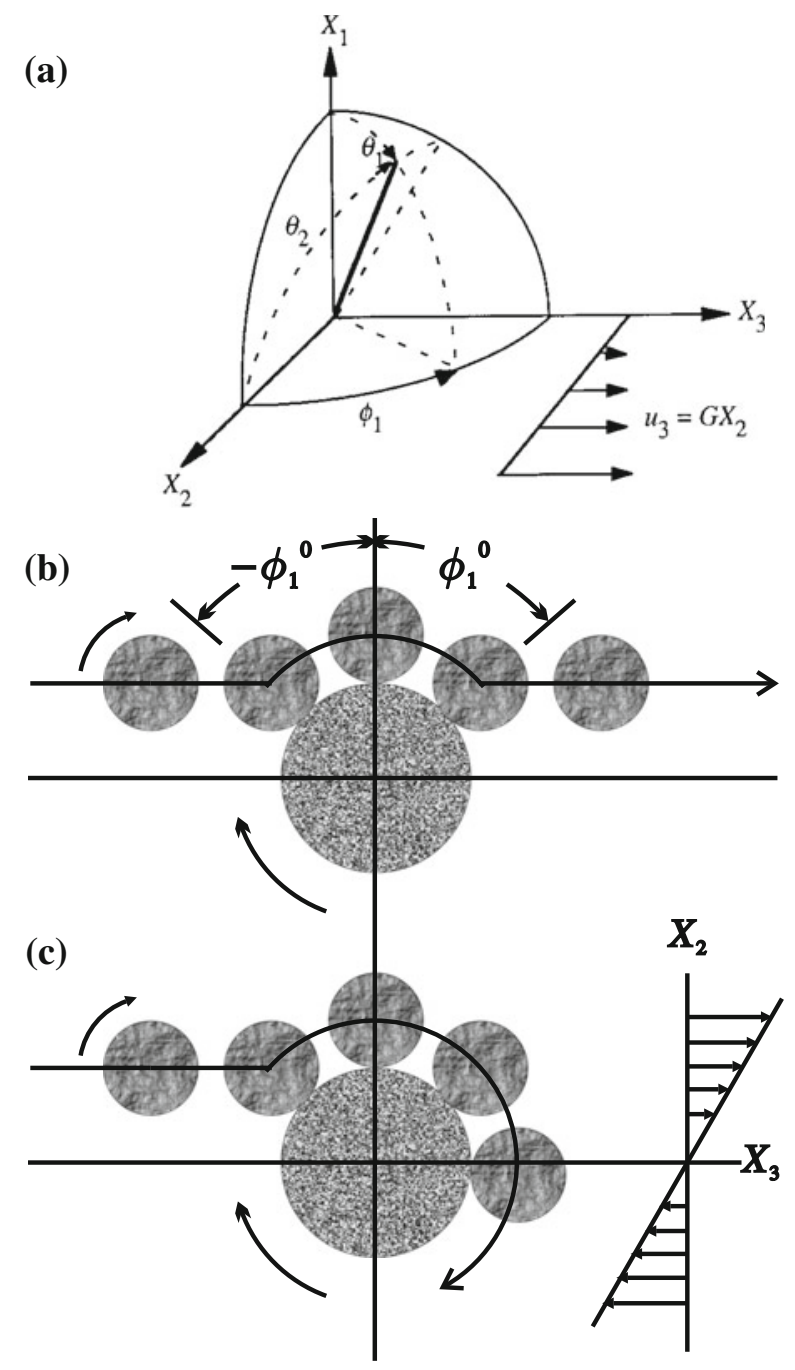

FIGURE 1. Schematic of two-body collisions between un-equal sized spheres in Couette flow. (a) Two spheres are placed in Cartesian $\left(X_{1}, X_{2}, X_{3}\right)$ and spherical-polar $\left(\theta_{1}, \phi_{1}\right)$ coordinates where fluid velocity has a non-zero component along the $X_{3}$ direction with $u_{3}=G X_{2}$. Transient (b) and nonseparating (c) doublets were formed under shear flow by taking the center of large sphere as reference. Supposing two spheres collide and make apparent contact at $\phi_{1}=-\phi_{1}^{0}$, specific receptor-ligand bonds will form or dissociate due to their stochastic nature. If there is no bonds linking the spheres at the end moment of contact duration, the two separate at $\phi_{1}=\phi_{1}^{0}$ in a mirror-image pattern, so-called transient doublet (b). Non-separating doublets are denoted as those spheres linked by receptor-ligand bonds at angle $\phi_{1}^{0}$ and remain attached under applied force for numerous rotations (c).

receptors and ligands to encounter each other. Supposing two cells collide and make apparent contact at $\phi_{1}=-\phi_{1}^{0}$, the specific receptor-ligand bonds will form or break-up during one cycle of the contact. If there is no bond linking the cells at the end moment of a prescribed contact period, the two cells will separate at $\phi_{1}=\phi_{1}^{0}$ in a mirror-image manner, ${ }^{2,9}$ which is so-called a transient doublet (Fig. 1b). Otherwise, the doublet will remain attached under hydrodynamic 
force until all the bonds break-up, which is then called non-separating doublet (Fig. 1c).

For a transient doublet rotating from $-\phi_{1}^{0}$ to $\phi_{1}^{0}$, the corresponding contact duration was given by $\tau\left(\phi_{1}^{0}\right)=2\left(r_{\mathrm{e}}+1 / r_{\mathrm{e}}\right) \tan ^{-1}\left(\tan \phi_{1}^{0} / r_{\mathrm{e}}\right) / G^{2}$ Here $r_{\mathrm{e}}$ is the equivalent ellipsoidal axis ratio of doublet that behaves like an ellipsoid in shear flow, e.g., $r_{\mathrm{e}}=1.56$ for $r_{1} / r_{2}=2$ or 1.98 for $r_{1} / r_{2}=1{ }^{1}$ By assuming a rectilinear approach of the colliding cells, the mean value of the encounter duration of all transient doublets could be integrated as ${ }^{2}$ :

$$
\bar{\tau}=\frac{\pi\left(r_{\mathrm{e}}+1 / r_{\mathrm{e}}\right)}{G\left(r_{\mathrm{e}}+1\right)} .
$$

\section{Hydrodynamic Forces Acting on the Doublet in Shear Flow}

The normal force $\left(F_{\mathrm{N}}\right)$ acting along and the shear force $\left(F_{\mathrm{S}}\right)$ acting normal to the major axis of a doublet in a shear flow were given by ${ }^{39}$

$$
\begin{gathered}
F_{\mathrm{N}}=\alpha_{\mathrm{N}} \eta G r_{1}^{2} \sin ^{2} \theta_{1} \sin 2 \phi_{1} \\
F_{\mathrm{S}}=\alpha_{\mathrm{S}} \eta G r_{1}^{2} \sin \theta_{1}\left[\cos ^{2} \theta_{1} \sin ^{2} 2 \phi_{1}+\cos ^{2} 2 \phi_{1}\right]^{1 / 2}
\end{gathered}
$$

where $\alpha_{\mathrm{N}}$ and $\alpha_{\mathrm{S}}$ are force coefficients as a function of the dumbbell geometry, and $\eta$ is the medium viscosity. For non-separating doublet, the hydrodynamic forces are periodic functions with periods of $T / 2$ for $F_{\mathrm{N}}$ and $T / 4$ for $F_{\mathrm{S}}$, respectively, where $T\left(=2 \pi\left(r_{\mathrm{e}}+1 / r_{\mathrm{e}}\right) / G\right)$ is the period of doublet rotation.

Since shear force has little impact on doublet breakage, only normal force was taken into account for forced dissociation of formed bonds linking the two cells. ${ }^{27}$ Also, the compressive part of the normal force was assumed to be carried by the solid spheres instead of the receptor-ligand bonds. By substituting the relationship between the polar $\left(\theta_{1}\right)$ and azimuthal $\left(\phi_{1}\right)$ angles in each orbit, $\tan \theta_{1}=C_{\mathrm{O}} r_{\mathrm{e}} /\left(r_{\mathrm{e}}^{2} \cos ^{2} \phi_{1}+\right.$ $\left.\sin ^{2} \phi_{1}\right)^{1 / 2}, 2$ where $C_{\mathrm{O}}$ is the orbit constant, to eliminate $\left(\theta_{1}\right)$ from Eq. (3a), the force acting on the bonds gave:

$$
F\left(\phi_{1}\right)=\left\{\begin{array}{ll}
\alpha_{\mathrm{N}} \eta G r_{1}^{2} \frac{C_{r_{\mathrm{e}}^{2}\left(C_{\mathrm{O}}^{2}+\cos ^{2} \phi_{1}^{2} \sin 2 \phi_{1}\right.}^{2 \sin ^{2} \phi_{1}}}{} \\
i \pi \leq \phi_{1}<(i+1 / 2) \pi \\
0 \quad(i+1 / 2) \pi \leq \phi_{1}<(i+1) \pi
\end{array} .\right.
$$

\section{Doublet Formation by Two-Body Collision}

A well-developed probabilistic kinetics model was adapted here to describe the binding kinetics of a small number of receptor-ligand bonds for two contacted cells $^{5,7,29}$ :

$$
\begin{aligned}
d p_{n} / d t= & A_{\mathrm{c}} m_{\mathrm{r}} m_{\mathrm{l}} k_{\mathrm{f}} p_{n-1}-\left(A_{\mathrm{c}} m_{\mathrm{r}} m_{\mathrm{l}} k_{\mathrm{f}}+n k_{\mathrm{r}}^{(n)}\right) p_{n} \\
& +(n+1) k_{\mathrm{r}}^{(n+1)} p_{n+1} .
\end{aligned}
$$

Here, $p_{n}$ is the probability of having $n$ bonds at time $t ; A_{\mathrm{c}}$ is the contact area of two cells; $m_{\mathrm{r}}$ and $m_{1}$ are the respective site densities of receptor and ligand; $k_{\mathrm{f}}$ is the forward rate of receptor-ligand pair; and $k_{\mathrm{r}}^{(n)}$ is the reverse rate for the dissociation of $n$-th bond. Mechanical force applied to the formed doublets is likely to accelerate the dissociation of existing bonds and the reverse rate was described by Bell Model ${ }^{3}$ :

$$
k_{\mathrm{r}}^{(n)}=k_{\mathrm{r}}^{0} \exp \left(a F(t) /\left(n k_{\mathrm{B}} T_{\mathrm{K}}\right)\right),
$$

where $k_{\mathrm{r}}^{0}$ is the zero-force reverse rate; $a$ is the interaction range; $F(t)$ is the force shared among $n$ bonds; $k_{\mathrm{B}}$ is the Boltzmann constant; and $T_{\mathrm{K}}$ is the absolute temperature.

With the initial condition that no bond exists at the beginning of two-body collision, the probability of having $n$ bonds at the end moment of the collision was described by a probability vector $\left\{p_{\mathrm{c} 0}, p_{\mathrm{c} 1}, \ldots\right.$, $\left.p_{\mathrm{c} n}, \ldots, p_{\mathrm{c} N}\right\}$. The subscript $N$, defined as the maximum number of bonds possibly to mediate the doublet, depends on the product of the contact area and the minimum value of $m_{\mathrm{r}}$ and $m_{\mathrm{l}}$. The collision capture efficiency, denoted as the probability of cell-cell collision to form non-separating doublets, was given as:

$$
\varepsilon=1-p_{\mathrm{c} 0} .
$$

In the case of applied force $F=0$ (i.e., $k_{\mathrm{r}}^{(n)} \sim k_{\mathrm{r}}^{0}$ ), Eq. (5) was able to be solved analytically using the approach of probability-generating function and the solution results in the Poisson distribution: $p_{\mathrm{c} n} \approx$ $\left(A_{\mathrm{c}} m_{\mathrm{r}} m_{\mathrm{l}} k_{\mathrm{f}} \bar{\tau}\right)^{n} \exp \left(-A_{\mathrm{c}} m_{\mathrm{r}} m_{\mathrm{l}} k_{\mathrm{f}} \bar{\tau}\right) / n !{ }^{27}$ With a short contact duration ( $\bar{\tau}, \sim 0.01-0.1 \mathrm{~s})$, the doublet formed by two-body collision is most likely linked by one bond, i.e. $\varepsilon \approx A_{\mathrm{c}} m_{\mathrm{r}} m_{\mathrm{l}} k_{\mathrm{f}} \bar{\tau}^{24,27}$ When a constant $F$ is applied to accelerate the reverse rate, Eq. (5) was able to be simplified to single bond case:

$$
d p_{1} / d t=A_{\mathrm{c}} m_{\mathrm{r}} m_{\mathrm{l}} k_{\mathrm{f}}\left(1-p_{1}\right)-k_{\mathrm{r}}^{(1)} p_{1} .
$$

The solution of Eq. (8) gives $p_{1}=A_{\mathrm{c}} m_{\mathrm{r}} m_{\mathrm{l}} k_{\mathrm{f}}$ $\left\{1-\exp \left[-\left(A_{\mathrm{c}} m_{\mathrm{r}} m_{\mathrm{l}} k_{\mathrm{f}}+k_{\mathrm{r}}^{(1)}\right) \bar{\tau}\right]\right\} /\left(A_{\mathrm{c}} m_{\mathrm{r}} m_{\mathrm{l}} k_{\mathrm{f}}+k_{\mathrm{r}}^{(1)}\right)$, from which the collision capture efficiency yielded:

$$
\varepsilon \approx A_{\mathrm{c}} m_{\mathrm{r}} m_{\mathrm{l}} k_{\mathrm{f}} \bar{\tau} .
$$

Interestingly, $\varepsilon$ is only governed by the forward rate but not the reverse rate. This is because the time for both doublet formation $\left(1 / A_{\mathrm{c}} m_{\mathrm{r}} m_{\mathrm{l}} k_{\mathrm{f}}, \sim 1-100 \mathrm{~s}\right)$ and breakage $\left(1 / k_{\mathrm{f}}, \sim 1-100 \mathrm{~s}\right)$ is much higher than the two-body collision duration $\bar{\tau}$, indicating that the bond 
formation and breakage is extremely rare during the collision. Once the bond forms, it is unlikely to breakup. In this regard, even when the force is not a constant, the collision capture efficiency was able to be estimated by Eq. (9).

\section{Master Equations for Cell Aggregation and Disaggregation}

Doublet formation and breakage described above continue to occur throughout the entire duration on shear-induced cell-cell collision. Once a doublet forms, the existing bonds may break up or more bonds may form, due to the stochastic nature of receptor-ligand interaction (cf. Eq. 5). When the last bond linking the cells breaks up, the doublet separates into two singlets and will not be in contact anymore. Thus, there are two subgroups of the cells presenting in the suspension: the first is singlet ensemble having zero-bond probability, $p_{0}$, and the second is doublet ensemble having $n$-bond probability vector, $\left\{p_{1}, p_{2}, \ldots, p_{n}, \ldots, p_{N}\right\}$. The transition probability from zero-bond to $n$-th bond by twobody collision (i.e., from singlet to doublet) yields $f_{\mathrm{c}} p_{\mathrm{c} n}$ following McQuarrie's theorem. ${ }^{29}$ Master equations for cell aggregation dynamics were then written as:

$$
\left\{\begin{array}{l}
\frac{d p_{0}}{d t}=-f_{\mathrm{c}} \varepsilon p_{0}+k_{\mathrm{r}}^{(1)} p_{1} \\
\begin{array}{l}
\frac{d p_{1}}{d t}=f_{\mathrm{c}} p_{\mathrm{c} 1} p_{0}-\left(A_{\mathrm{c}} m_{\mathrm{r}} m_{\mathrm{l}} k_{\mathrm{f}}+k_{\mathrm{r}}^{(1)}\right) p_{1}+2 k_{\mathrm{r}}^{(2)} p_{2} \\
\vdots \\
\frac{d p_{n}}{d t}=f_{\mathrm{c}} p_{\mathrm{c} n} p_{0}+A_{\mathrm{c}} m_{\mathrm{r}} m_{\mathrm{l}} k_{\mathrm{f}} p_{n-1} \\
\quad-\left(A_{\mathrm{c}} m_{\mathrm{r}} m_{\mathrm{l}} k_{\mathrm{f}}+n k_{\mathrm{r}}^{(n)}\right) p_{n}+(n+1) k_{\mathrm{r}}^{(n+1)} p_{n+1} \\
\vdots \\
\frac{d p_{N}}{d t}=f_{\mathrm{c}} p_{\mathrm{c} N} p_{0}+A_{\mathrm{c}} m_{\mathrm{r}} m_{\mathrm{l}} k_{\mathrm{f}} p_{N-1}-N k_{\mathrm{r}}^{(N)} p_{N}
\end{array}
\end{array}\right.
$$

Here $C_{1}=C_{10}-C_{20}\left(1-p_{0}\right)$. Specially, if the two cells have same concentration (i.e., $C_{10}=C_{20}$ ), the first term on the right-hand side $\left(f_{\mathrm{c}} p_{\mathrm{c} n} p_{0}\right)$ was simplified to $f_{\mathrm{c} 0} p_{\mathrm{c} n} p_{0}^{2}$ by substituting $f_{\mathrm{c}}$ with $f_{\mathrm{c} 0} p_{0}$, where $f_{\mathrm{c} 0}=4\left(r_{1}+r_{2}\right)^{3} G C_{10} / 3$.

Note that, in contrast to Eq. (5) for two cells keeping in contact all the time, Eq. (10) developed in the current work is for two cells only in contact when they collide or have bonds linking them. As compared to the previous model, ${ }^{27}$ the major difference lies in the $f_{\mathrm{c}} \varepsilon p_{0}$ term on the right-hand side in the first equation $\left(d p_{0} / d t\right)$ and the $f_{\mathrm{c}} p_{\mathrm{c} n} p_{0}$ term on the right-hand side in the following equations $\left(d p_{n} / d t, n>0\right)$, which takes into consideration of the transition from singlet to $n$-bond doublet upon cell-cell collision. Combined with the aforementioned issue that new-born doublets are most likely linked by only one bond initially, the master equations are simplified by setting $p_{\mathrm{c} 1}=\varepsilon$ and $p_{\mathrm{c} n}=0(n=2,3, \ldots)$ :

$$
\left\{\begin{array}{l}
\frac{d p_{0}}{d t}=-f_{\mathrm{c}} \varepsilon p_{0}+k_{\mathrm{r}}^{(1)} p_{1} \\
\vdots \\
\frac{d p_{n}}{d t}=-A_{\mathrm{c}} m_{\mathrm{r}} m_{\mathrm{l}} k_{\mathrm{f}} p_{n}+(n+1) k_{\mathrm{r}}^{(n+1)} p_{n+1}-\sum_{i=0}^{n-1} \frac{d p_{i}}{d t} \\
\vdots \\
\frac{d p_{N}}{d t}=-\sum_{i=0}^{N-1} \frac{d p_{i}}{d t}
\end{array}\right.
$$

\section{Application of the Model to the Measurements}

The above model was developed for heterotypic aggregation dynamics between two unequal-sized spheres and is able to apply in different cases of aggregation between tumor cells and neutrophils. ${ }^{10,17,18,24,31}$ In some cases of homotypic aggregation with same-sized population of spheres such as neutrophil aggregation, ${ }^{32,47}$ the collision frequency per unit volume is simplified by $16 r^{3} G C^{2} / 3$ (where $r$ and $C$ are the sphere radius and concentration, respectively) and the transition probability from zero-bond to $n$-th bond yields $32 r^{3} G C \varepsilon / 3$. By comparing with the formulation for heterotypic aggregation $\left(f_{c} \varepsilon=4\left(r_{1}+r_{2}\right)^{3} G C_{1} \varepsilon / 3\right)$, the model is applicable to simulate the homotypic aggregation just by replacing $r_{1}$ and $r_{2}$ to $r$ as well as $C_{1}$ to $C$.

For experimental measurements of shear-induced cell aggregation and disaggregation performed in a cone-plate viscometer, the time course of percentage of cell aggregation was determined either from microscopic observations directly $y^{21,48,49}$ or by a twocolor flow cytometry technique ${ }^{10,17,18,24,28,31,32,47,51}$ : $\%$ aggregation $=$ (number of cells/beads in aggregates $) /$ (total number of cells/beads in suspension) $\times 100$. The resulted data were compared with the adhesion fraction $P_{\mathrm{a}}(t) \times 100=\left[1-p_{0}(t)\right] \times 100$ predicted from the above model and the intrinsic kinetic parameters of interacting molecules are able to be determined from the best-fit of the data.

\section{Numerical Calculations and Data Analysis}

A Runge-Kutta numerical scheme and a modified Levenberg-Marquart method were used to fit the 
TABLE 1. Parameters used in the model.

\begin{tabular}{llll}
\hline & \multicolumn{3}{c}{ Values and references $^{2}$} \\
\cline { 2 - 4 } Parameters & Homotypic $^{\mathrm{a}}$ & Heterotypic $^{\mathrm{b}}$ & PMN-WM9 $^{\mathrm{C}}$ \\
\hline Radius of cell/bead 1, $r_{1}(\mu \mathrm{m})$ & $2.38^{21}$ & $6.00^{31}$ & $8.00^{24}$ \\
Radius of cell/bead 2, $r_{2}(\mu \mathrm{m})$ & $\mathrm{N} / \mathrm{A}$ & $3.75^{31}$ & $4.00^{24}$ \\
Concentration of cell/bead 1, $C_{10}\left(\times 10^{12} \mathrm{~m}^{-3}\right)$ & $8.0^{27}$ & 5.0 or $6.0^{31}$ & $1.0^{24}$ \\
Concentration of cell/bead 2, $C_{20}\left(\times 10^{12} \mathrm{~m}^{-3}\right)$ & $\mathrm{N} / \mathrm{A}$ & $3.0^{31}$ & $1.0^{24}$ \\
Mean value of angle factor, $\left\langle C_{\mathrm{f}}\right\rangle$ & $0.950^{27}$ & $0.967^{27}$ & $0.967^{27}$ \\
Equivalent axis ratio of doublet, $r_{\mathrm{e}}$ & $1.98^{1}$ & $1.73^{1}$ & $1.56^{1}$ \\
Normal force coefficient, $\alpha_{\mathrm{N}}$ & $19.33^{49}$ & $12.0^{39}$ & $8.5^{39}$ \\
Shear force coefficient, $\alpha_{\mathrm{S}}$ & $7.02^{49}$ & $6.0^{39}$ & $4.0^{39}$ \\
\hline
\end{tabular}

${ }^{a}$ Only one type of bead was used in homotypic aggregation. ${ }^{21}$

${ }^{\mathrm{b}}$ In heterotypic aggregation, cell/bead 1 is referred to E3-ICAM cell and cell/bead 2 is denoted as PMN. ${ }^{31}$

${ }^{\mathrm{C}}$ In heterotypic aggregation, cell/bead 1 is referred to WM9 melanoma cell and cell/bead 2 is denoted as PMN. ${ }^{24}$

probabilistic model. The parameter values used in the calculation are listed in Table 1. The master equations (Eqs. 5, 11) were then solved numerically by transforming the independent variable from time $t$ to polar angle $\phi_{1}$ using the relationship ${ }^{50}$ :

$$
\begin{aligned}
\frac{d \phi_{1}}{d t} & =\frac{G}{2}\left(1+\frac{r_{\mathrm{e}}^{2}-1}{r_{\mathrm{e}}^{2}+1} \cos 2 \phi_{1}\right) \\
& =\frac{G}{r_{\mathrm{e}}^{2}+1}\left(r_{\mathrm{e}}^{2} \cos ^{2} \phi_{1}+\sin ^{2} \phi_{1}\right) .
\end{aligned}
$$

To calculate the bond formation upon a single collision event (i.e., $p_{\mathrm{c} n}$ ) with no bond initially, Eq. (5) was first calculated from $\phi_{1}=2 \pi-\phi_{1}^{0}$ to $\phi_{1}=2 \pi+\phi_{1}^{0}$, where $\phi_{1}^{0}=\tan ^{-1}\left[r_{\mathrm{e}} \tan \left(0.5 \pi /\left(r_{\mathrm{e}}+1\right)\right)\right]$. For the time course of cell aggregation dynamics under shear flow, Eq. (11) was then calculated over the entire duration with the initial values of $p_{0}=1$ and $p_{n}=0(n=1$, $2, \ldots)$ at $t=0\left(\phi_{1}=0\right)$. Best-fit of numerical calculations to measured data was obtained by adjusting a set of kinetic parameters that minimized the error $\left(\chi^{2}\right)$ between the data and the predictions. ${ }^{37}$ The $\chi^{2}$ statistic, or weighted sum of square of errors, is defined by $\chi^{2}=\sum_{i=1}^{M}\left[y_{i}-y\left(x_{i}\right)\right]^{2} / \sigma_{i}^{2}$, where $y_{i}, y\left(x_{i}\right)$, and $\sigma_{i}$ are the measurement, prediction, and standard deviation at $x_{i}$, respectively, and $M$ is the number of data points.

\section{RESULTS}

\section{Application in Homotypic Aggregation}

A kinetic mode ${ }^{27}$ has been developed previously to predict shear-induced homotypic doublet formation and breakage of latex beads (or red blood cells) and to estimate the intrinsic forward and reverse rates of interacting molecular pair by fitting the data with the model, where doublets were first allowed to form at a low shear rate and then were subjected to a high shear rate to break up. ${ }^{21,48,49}$ The limitations of the previous model lie in: (1) doublet breakage at low shear rate and the subsequent doublet formation at high shear rate were neglected; (2) contact duration between two singlets might be over-estimated by keeping the singlets in contact all the time; and (3) the model, even simplified, was still complicated to the exact process described above (i.e., low shear induces doublet formation first and then high shear enforces doublet breakage). Here we first validated the current model by fitting it to the same data set of latex beads cross-linked by protein $\mathrm{G}-\mathrm{IgG}$ bonds ${ }^{21}$ and then compared the predictions with those previously described. ${ }^{27}$

\section{Model Validation and Fitted Kinetic Parameters}

Global fittings were performed for all data points at high shear rates $\left(F_{\mathrm{N} \text {, max }}=85\right.$ and $\left.185 \mathrm{pN}\right)$ to estimate a set of three parameters $\left[k_{\mathrm{r}}^{0}, a\right.$, and $\left.A_{\mathrm{c}} m_{\mathrm{r}} m_{\mathrm{l}} k_{\mathrm{f}}\right]$. Using the systematically varied initial values, it was found that the model (lines) fits the data (points) well (Fig. 2), indicating that the model is feasible and reliable. Two sets of kinetic parameters were obtained from the model by best-fitting the data. With the first set of parameters $\left(k_{\mathrm{r}}^{0}=1.35 \mathrm{~s}^{-1}, a=0.046 \mathrm{~nm}\right.$ and $A_{\mathrm{c}} m_{\mathrm{r}} m_{\mathrm{l}} k_{\mathrm{f}}=6.12 \mathrm{~s}^{-1}$ with $\left.\chi^{2}=1.39\right)$, doublet formation induced by low shear rate reached the equilibrium quickly ( $\sim 60 \mathrm{~s})$ and the doublet so formed dissociated very fast (Fig. 2a). With the second set of parameters $\left(k_{\mathrm{r}}^{0}=8.73 \times 10^{-3} \mathrm{~s}^{-1}, a=0.30 \mathrm{~nm}\right.$ and $A_{\mathrm{c}} m_{\mathrm{r}} m_{\mathrm{l}} k_{\mathrm{f}}=$ $5.31 \times 10^{-1} \mathrm{~s}^{-2}$ with $\chi^{2}=4.23$ ), by contrast, the percentage of aggregation increased very slowly even without saturating the equilibrium at $30 \mathrm{~min}$ and the doublet break-up was quite slow under high shear (Fig. 2b).

While no kinetic parameters for protein G-IgG bond have been reported to our knowledge, only the breakage of protein A-IgG bond was studied in the 

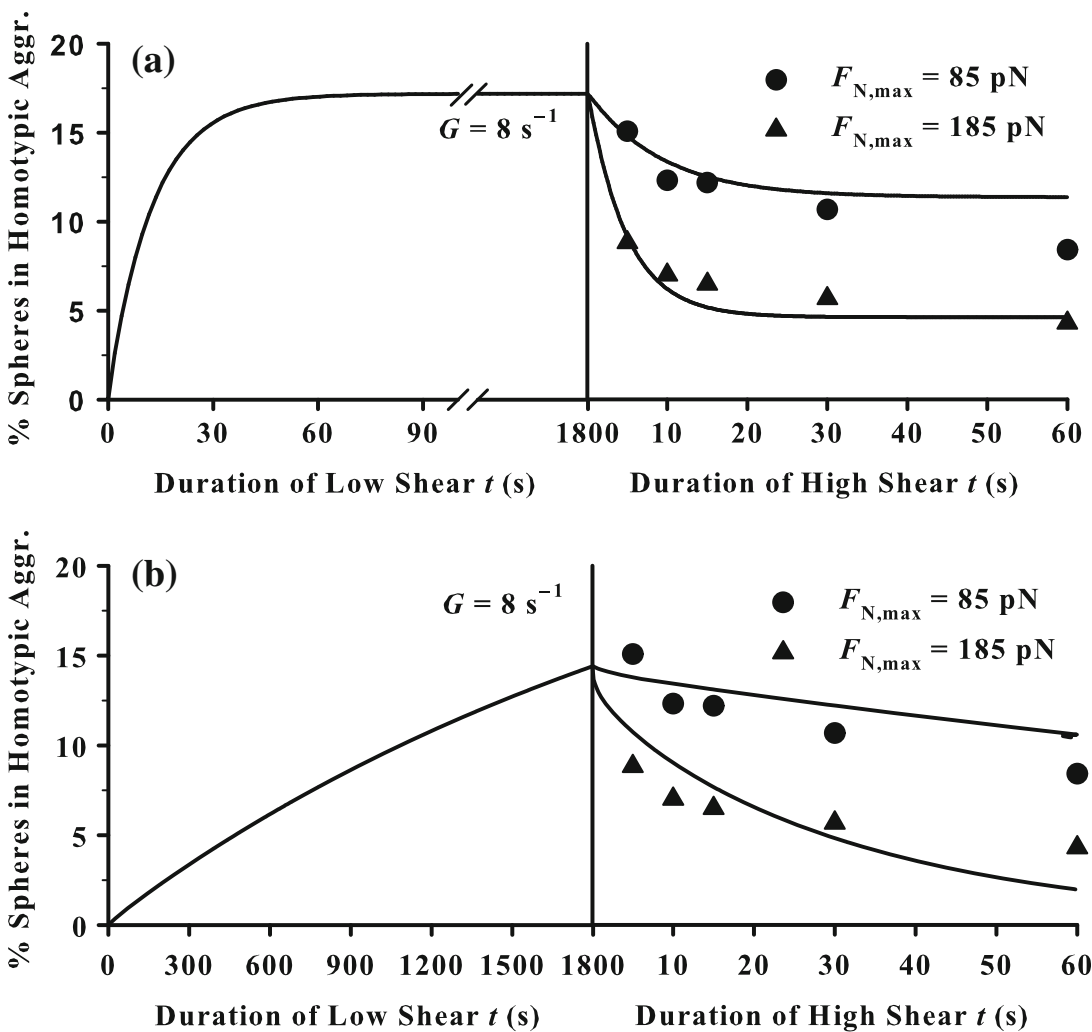

FIGURE 2. Comparison between the data (points) and the predictions (solid lines) by best-fitted parameters: (a) $k_{\mathrm{r}}^{0}=1.35 \mathrm{~s}^{-1}$, $a=0.046 \mathrm{~nm}$ and $A_{\mathrm{c}} m_{\mathrm{r}} m_{\mathrm{l}} k_{\mathrm{f}}=6.12 \mathrm{~s}^{-1}$ with $\chi^{2}=1.39$ and (b) $k_{\mathrm{r}}^{0}=8.73 \times 10^{-3} \mathrm{~s}^{-1}, a=0.30 \mathrm{~nm}$ and $A_{\mathrm{c}} m_{\mathrm{r}} m_{\mathrm{l}} k_{\mathrm{f}}=5.31 \times 10^{-1} \mathrm{~s}^{-1}$ with $\chi^{2}=4.23$. Data were adopted from the population study of doublet of latex beads cross-linked by protein G-IgG bonds ${ }^{21}$ by converting the fraction of doublet break-up $\left(P_{\mathrm{b}}\right)$ to the aggregation percentage $\left(P_{\mathrm{a}}\right)$ by $P_{\mathrm{a}}=P_{\mathrm{a}}^{30} \times\left(1-P_{\mathrm{b}}\right)$ for numerical calculations, where $P_{\mathrm{a}}^{30}$ is the equilibrium aggregation percentage at $30 \mathrm{~min}(=19.2 \pm 4.85 \%)$.

literatures using a biomembrane force probe approach with the estimated values of reverse rate $k_{\mathrm{r}}^{0} \sim 0.12 \mathrm{~s}^{-1}$ and interaction range $a \sim 0.74 \mathrm{~nm} .^{42}$ More generally, the value of $a$ was found to be in the order of $0.3 \mathrm{~nm}$ for most of protein-protein bond (e.g., streptavidinbiotin, antibody-antigen) and in the order of $0.05 \mathrm{~nm}$ for protein-carbohydrate bond (e.g., selectin-ligand, integrin-ligand). ${ }^{30,49}$ In this regard, although the goodness-of-fit in Fig. 2a was better than that in Fig. $2 b\left(\chi^{2}=1.39\right.$ and 4.23 , respectively), the values obtained from latter one seemed to be more reasonable, which are also comparable to those described previously $\left(k_{\mathrm{r}}^{0}=8.05 \times 10^{-3} \mathrm{~s}^{-1}, a=0.31 \mathrm{~nm}, A_{\mathrm{c}} m_{\mathrm{r}} m_{\mathrm{l}} k_{\mathrm{f}}^{\mathrm{L}}=\right.$ $34.6 \times 10^{-3} \mathrm{~s}^{-1}$ and $\left.A_{\mathrm{c}} m_{\mathrm{r}} m_{\mathrm{l}} k_{\mathrm{f}}^{\mathrm{H}}=5.23 \times 10^{-3} \mathrm{~s}^{-1}\right) .{ }^{27}$ Furthermore, the prediction in Fig. 2b was in excellent agreement with the measurement that it takes $\sim 30 \mathrm{~min}$ to reach a $\sim 20 \%$ aggregation percentage. ${ }^{21}$

\section{Doublet Formation at Low Shear Rate}

In previous studies of doublet break-up under shear flow, ${ }^{21,48,49}$ bond number at the end moment of low shear was assumed to follow a Poisson distribution. ${ }^{4}$ Noting that the kinetic theory employed was initially developed for a cell centrifugation assay and further observed in a micropipette adhesion frequency assay where cells were kept in contact all the time, ${ }^{5}$ this should be a distinct case for many published results derived from a cone-plate viscometer assay, in which the two cells/beads are brought into transient contact to allow bond formation only during the interval of two-body collision. Obviously, neglecting the impact of short-term contact would overestimate the re-formation of doublets, especially during a 30-min low-shear period. We took this issue into a consideration in the current model (Eq. 11) and denoted the contact interval as $f_{\mathrm{c}} \varepsilon \approx f_{\mathrm{c}} A_{\mathrm{c}} m_{\mathrm{r}} m_{\mathrm{l}} k_{\mathrm{f}} \bar{\tau}$, which is $f_{\mathrm{c}} \bar{\tau}$-fold ( $\sim 0.003$; independent of shear rates) of $A_{\mathrm{c}} m_{\mathrm{r}} m_{\mathrm{l}} k_{\mathrm{f}}$ that proposed in the previous model. ${ }^{27}$ Moreover, the previous model ${ }^{27}$ defined the doublet formation and survival during low shear period ( $\sim 30 \mathrm{~min})$ by neglecting the decrease of singlet concentration due to the doublet formation, suggesting that the doublet number increases all the time over the entire low-shear period. This speculation would not affect much for small ensemble of formed doublet but result in a dramatic deviation for large ensemble of doublets. 
(a)

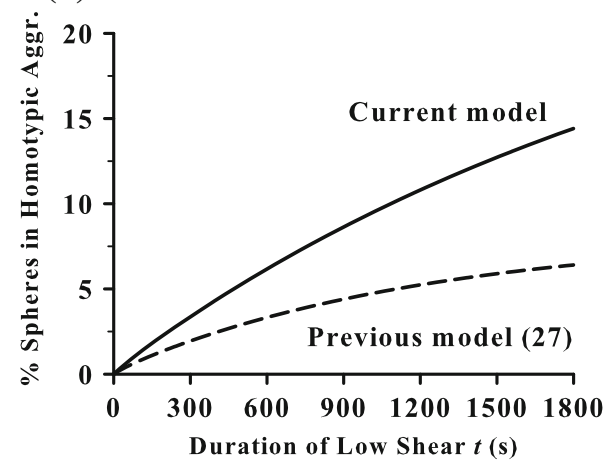

(b)

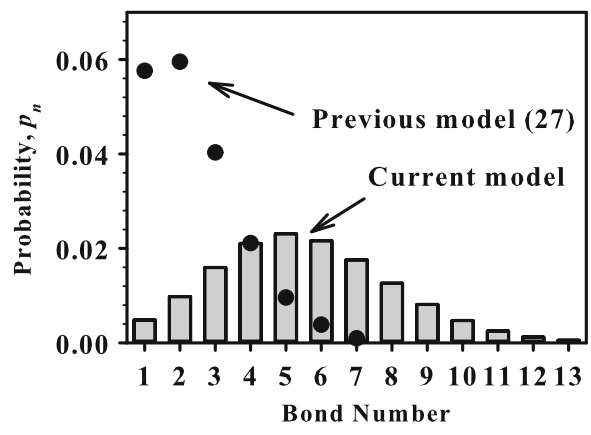

FIGURE 3. Comparison between the current model and the previous model ${ }^{27}$ at low shear. (a) Time course of cell aggregation at low shear rate period was calculated with the parameters from current model $k_{\mathrm{r}}^{0}=8.73 \times 10^{-3} \mathrm{~s}^{-1}, a=0.30 \mathrm{~nm}$ and $A_{\mathrm{c}} m_{\mathrm{r}} m_{\mathrm{l}} k_{\mathrm{f}}=5.31 \times 10^{-1} \mathrm{~s}^{-1}$ (solid line) and with the parameters from previous model $k_{\mathrm{r}}^{0}=8.05 \times 10^{-3} \mathrm{~s}^{-1}, a=0.31 \mathrm{~nm}$ and $A_{\mathrm{c}} m_{\mathrm{r}} m_{1} k_{\mathrm{f}}^{\mathrm{f}}=34.6 \times 10^{-3} \mathrm{~s}^{-1}$ (dashed line). (b) Probability distribution of number of bonds at the end moment of low shear was calculated using the current model (bars) and compared with that from the previous model ${ }^{27}$ (points, by multiplying 0.192 ).

We compared the calculations of doublet formation in the first 30 min between the current model and the previous model. ${ }^{27}$ Using the same set of kinetic parameters obtained previously, ${ }^{27}$ the current model predicted a quite low bead aggregation $(6.41 \%$ vs. $\sim 19.2 \%$ ) (Fig. 3a), indicating that the doublet formation was overestimated in the previous model. This is not surprising since two singlets resulting from a newly-broken doublet are assumed to be separated from each other spontaneously in the current model while they were considered to keep in physical contact even with zero bonds in the previous model. We further tested the bond distribution at the end moment of low shear. As shown in Fig. 3b, more bonds were formed in a doublet (bars, the mean value $\langle n\rangle=5.56$ ) in the current calculations than that reported by the previous model (points, $\langle n\rangle=2.42$ ) ${ }^{27}$ While high $\langle n\rangle$ estimated here mainly contributed to the distinct probability transferring from 0 to 1 bond $(0.003 \times$ $\left.A_{\mathrm{c}} m_{\mathrm{r}} m_{\mathrm{l}} k_{\mathrm{f}}\right)$ with that transferring from $n$ to $n+1$ bond $(n \geq 1)\left(1.0 \times A_{\mathrm{c}} m_{\mathrm{r}} m_{\mathrm{l}} k_{\mathrm{f}}\right)$, low $\langle n\rangle$ predicted from the previous model was presumably attributed to the assumption that the non-separation of newly-formed singlets still have the transition probability $(1.0 \times$ $\left.A_{\mathrm{c}} m_{\mathrm{r}} m_{\mathrm{l}} k_{\mathrm{f}}\right)$.

\section{Doublet Break-Up at High Shear Rates}

At high shear rates, the prediction with the second set of kinetic parameters (line) yielded slight difference from the measurements (points) (Fig. 2b). Quick breakage of doublets either from very high $k_{\mathrm{r}}^{0}$ or very few bonds linking two singlets should not be the case in the current study, since high $k_{\mathrm{r}}^{0}$ (as seen in Fig. 2a with the first set of kinetic parameters) is not biologically relevant and the average number of bonds is relatively high (bars in Fig. 3b). To address the inconsistency, we further tested the impact of bead concentration $\left(C_{0}\right)$ on doublet break-up. Systematically-varied bead concentration $\left(C_{0}=4 \times 10^{12}\right.$ to $\left.8 \times 10^{14} \mathrm{~m}^{-3}\right)$ were used to fit the data. The calculations indicated that, with an increase in $C_{0}$, the goodness-of-fit increases $\left(\chi^{2}\right.$ decreases) and $k_{\mathrm{r}}^{0}$ and $A_{\mathrm{c}} m_{\mathrm{r}} m_{\mathrm{l}} k_{\mathrm{f}}$ reduce but $a$ almost remains the same. As seen in Fig. $4 \mathrm{a}$, the prediction with a concentration of $C_{0}=8.0 \times 10^{13} \mathrm{~m}^{-3}$ had a better agreement with the data than that used an original concentration of $C_{0}=8.0 \times 10^{12} \mathrm{~m}^{-3}$ (cf. Fig. 2b) $\left(\chi^{2}=1.72\right.$ and 4.23 , respectively). Meanwhile, probability distribution of the number of bonds at the end moment of low shear rate shifted leftwards with a smaller average bond number $(\langle n\rangle=3.58$ and 5.56, respectively) (Fig. 4b) since the ratio $f_{\mathrm{c}} \bar{\tau}$ increased up to 0.3 when $C_{0}$ increased to $8.0 \times 10^{14} \mathrm{~m}^{-3}$, resulting in a Poisson-like distribution. Such a remarkable variation of bead concentration is experimentally possible with time even though a preset bead concentration $\left(C_{0}=8.0 \times 10^{12} \mathrm{~m}^{-3}\right)$ was given at the beginning of experiments. ${ }^{21,27}$ Since the density of latex beads $\left(1.055 \mathrm{~g} \mathrm{~cm}^{-3}\right)$ is slightly less than that of the medium $\left(1.081 \mathrm{~g} \mathrm{~cm}^{-3}\right)$, the majority of beads were potentially presented close to the upper cone wall after 30-min low shear, ${ }^{21}$ which may bias the "effective" bead concentration as much as up to $\sim 200$ folds by assuming that all the beads have risen to the vicinity of upper cone. While it is hard to determine the local deviation of bead concentration, these results presented here indicated that the bead distribution along shear field is crucial to determine the aggregation dynamics of colliding beads and the binding kinetics of interacting molecules.

Taken together, these predictions indicated that the model developed here was reliable not only in 

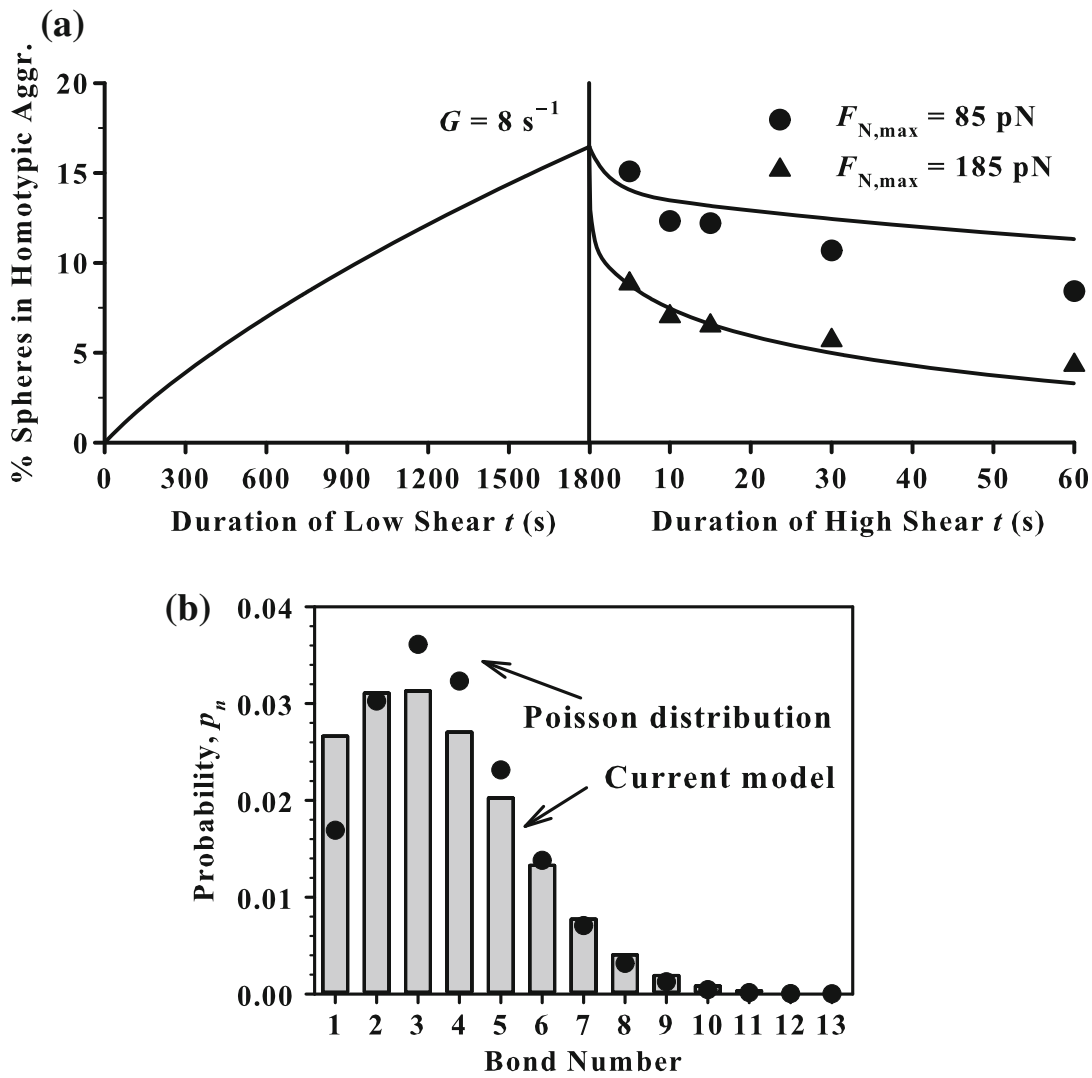

FIGURE 4. Prediction at high bead concentration of $C_{0}=8.0 \times 10^{13} \mathrm{~m}^{-3}$. (a) Comparison between the predictions (lines) plotted using best-fitted parameters $k_{\mathrm{r}}^{0}=8.90 \times 10^{-4} \mathrm{~s}^{-1}, a=0.41 \mathrm{~nm}$ and $A_{\mathrm{c}} m_{\mathrm{r}} m_{1} k_{\mathrm{f}}=5.27 \times 10^{-3} \mathrm{~s}^{-1}$ with $\chi^{2}=1.72$ and the data $(p o i n t s)$. (b) Probability distribution of bond number at the end moment of low shear (bars) compared with Poisson distribution with same average bond number $\langle n\rangle=3.58$ (points). Data (points) were adopted from the literature. ${ }^{21}$

reproducing the doublet formation and breakage processes but also in determining the kinetic parameters of interacting molecular pairs. Moreover, we clarified the fact that the two singlets from a doublet newly-broken could separate spontaneously rather than remain physical contact, which results in the reduction of contact duration and doublet formation.

\section{Application in Heterotypic Aggregation}

We also applied the model to predict the aggregation dynamics of two heterotypic cells. In a previous study, a transfected mouse $\mathrm{B} 78 \mathrm{H} 1$ melanoma cell line stably expressing human ICAM-1, so-called E3-ICAM cell, was subjected to shear in a cone-plate viscometer to form aggregates with human PMNs expressing $\beta_{2}$-integrin $\left(\alpha_{\mathrm{L}} \beta_{2}\right.$ and $\left.\alpha_{\mathrm{M}} \beta_{2}\right)$. Cell concentration ratio of E3/PMN ( 1.7-2.0) was used to assure that most aggregates were doublets and the aggregation percentage was determined by a two-color flow cytometry technique ${ }^{31}$ Distinct roles in $\alpha_{\mathrm{L}} \beta_{2}$ and $\alpha_{\mathrm{M}} \beta_{2}$ on PMNs binding to ICAM-1 on E3 cells under hydrodynamic shear flow were identified, i.e., both $\alpha_{\mathrm{L}} \beta_{2}$ and $\alpha_{\mathrm{M}} \beta_{2}$ contributed to the initial phase of cell adhesion while only $\alpha_{M} \beta_{2}$ was functional spanning over entire aggregation phase. Here we compared the data with our model, obtained the kinetic parameters for $\beta_{2}$-integrin and ICAM-1 interactions, and discussed the decay factor at both cellular and molecular levels.

\section{Model Prediction and Fitted Kinetic Parameters}

For homotypic aggregation of $\mathrm{PMNs}^{32,47}$ or heterotypic aggregation between $\mathrm{PMNs}$ and tumor cells $^{10,17,18,24,28,31}$ mediated by $\beta_{2}$-integrin and ligand interactions, the time course of aggregation fraction exhibits a transition phase where it first increases and then decreases with shear duration. While the underlying mechanisms remain unclear, such the time course is assumed to be correlated with the changes in the contact area $\left(A_{\mathrm{c}}\right)$, the receptor/ligand expression $\left(m_{\mathrm{r}} / m_{1}\right)$, as well as the molecular conformation. ${ }^{24}$ An exponentially decay was introduced to describe the decrease in adhesion efficiency at cellular level ${ }^{31,32}$

$$
E=E_{0} \exp \left(-\alpha_{\mathrm{c}} t\right),
$$

where $E_{0}$ and $E$ are the adhesion efficiency, respectively, at the moment immediately after PMN 
stimulation and at time $t$, and $\alpha_{\mathrm{c}}$ is the decay factor at cellular level. Similarly, an exponential-decay model for the effective forward rate was proposed in a previous work ${ }^{24}$

$$
A_{\mathrm{c}} m_{\mathrm{r}} m_{\mathrm{l}} k_{\mathrm{f}}=\left(A_{\mathrm{c}} m_{\mathrm{r}} m_{\mathrm{l}} k_{\mathrm{f}}\right)^{0} \exp \left(-\alpha_{\mathrm{m}} t\right)
$$

where $\left(A_{\mathrm{c}} m_{\mathrm{r}} m_{\mathrm{l}} k_{\mathrm{f}}\right)^{0}$ is the effective forward rate right after PMN stimulation and $\alpha_{\mathrm{m}}$ is the decay factor at molecular level. Here the intrinsic forward rate $k_{\mathrm{f}}$ was estimated in a lumped parameter $A_{\mathrm{c}} m_{\mathrm{r}} m_{\mathrm{l}} k_{\mathrm{f}}$ since one can not measure $A_{\mathrm{c}}$ accurately.

We applied the current model to compare with the measurements of heterotypic aggregation kinetics between PMNs and tumor cells ${ }^{31}$ in three different groups of (1) both $\alpha_{\mathrm{L}} \beta_{2^{-}}$and $\alpha_{\mathrm{M}} \beta_{2}$-dependent (eight curves), (2) $\alpha_{\mathrm{L}} \beta_{2}$-dependent by blocking $\alpha_{\mathrm{M}} \beta_{2}$ (two curves), and (3) $\alpha_{\mathrm{M}} \beta_{2}$-dependent by blocking $\alpha_{\mathrm{L}} \beta_{2}$ (two curves). Here Eq. (14) for decay factor at molecular level was merged into the master equations (Eq. 11) for data fitting. The following strategies were used in numerical calculations. A global fitting was first performed for each group to obtain a set of four parameters $\left[k_{\mathrm{r}}^{0}, a,\left(A_{\mathrm{c}} m_{\mathrm{r}} m_{\mathrm{l}} k_{\mathrm{f}}\right)^{0}\right.$, and $\left.\alpha_{\mathrm{m}}\right]$. Although the best-fitted $\alpha_{\mathrm{m}}$ for group (1) and (2) was slightly $<0$ $\left((-0.48\right.$ and -0.30$\left.) \times 10^{-3} \mathrm{~s}^{-1}\right)$, no significant increase was found in the aggregation curves (cf. points in Figs. 5a, 5b). So in those cases, $\alpha_{\mathrm{m}}$ was set to zero and a 3 -parameter global fitting was performed. An individual fitting for each binding curve was then conducted, at a fixed interaction range $a$ estimated from the global fitting, to obtain a set of three parameters $\left[k_{r}^{0},\left(A_{\mathrm{c}} m_{\mathrm{r}} m_{\mathrm{l}} k_{\mathrm{f}}\right)^{0}\right.$, and $\left.\alpha_{\mathrm{m}}\right]$. As seen in Fig. 5, the predictions (lines) were in an excellent agreement with the experimental data (points). Best-fitted kinetic parameters and decay factors obtained from individual fitting to the data were summarized in Table 2, where the kinetic rates of $\beta_{2}$-integrin-ICAM-1 interactions were comparable to those obtained from PMN-WM9 melanoma cell aggregation dynamics using a cone-plate viscometer assay. ${ }^{24}$ Molecular decay factor, $\alpha_{\mathrm{m}}$, for $\alpha_{\mathrm{L}} \beta_{2}$-dependent aggregation was much higher than those for both $\alpha_{\mathrm{L}} \beta_{2^{-}}$and $\alpha_{\mathrm{M}} \beta_{2^{-}}$-dependent or $\alpha_{\mathrm{M}} \beta_{2^{-}}$ dependent aggregation, supporting the previous conclusion that $\alpha_{\mathrm{L}} \beta_{2}$-integrin only contributes to cell
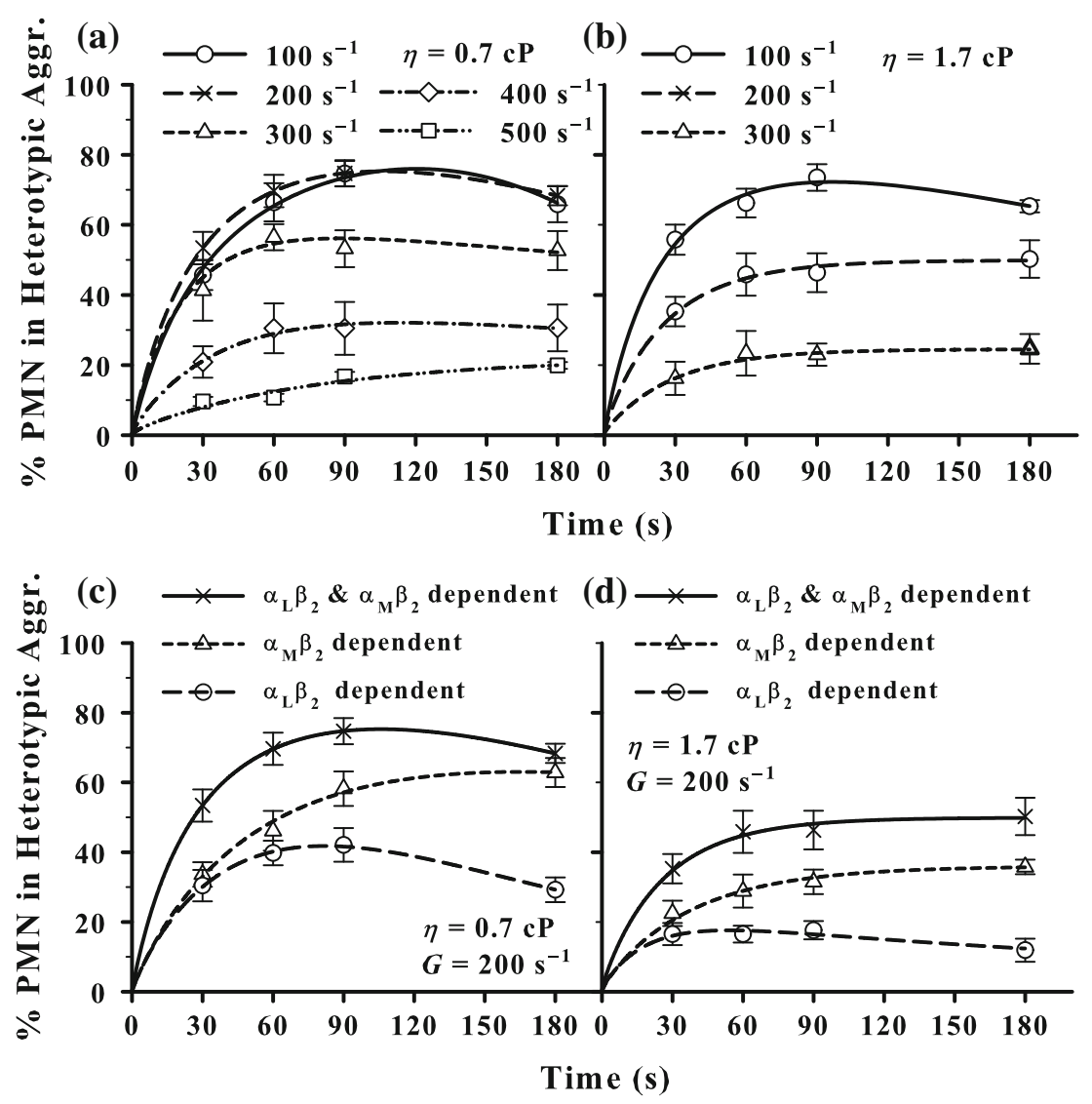

FIGURE 5. PMN-E3 aggregation mediated by $\beta_{2}$-integrin and ICAM-1 interactions. Numerical calculations (lines) were conducted for $\alpha_{L} \beta_{2^{-}}$and $\alpha_{M} \beta_{2^{-}}$-dependent aggregation with medium viscosity of 0.7 (a) and $1.7 \mathrm{cP}$ (b) as well as for $\alpha_{\mathrm{L}} \beta_{2^{-}}$or $\alpha_{\mathrm{M}} \beta_{2^{-}}$-dependent aggregation with viscosity of 0.7 (c) and $1.7 \mathrm{cP}$ (d). Data (points) were adopted from the literature. ${ }^{31}$ 
TABLE 2. Kinetic parameters of $\beta_{2}$-integrin-ICAM-1 bindings between PMNs and E3-ICAM cells.

\begin{tabular}{|c|c|c|c|c|c|}
\hline Data set & $k_{\mathrm{r}}^{0}\left(\mathrm{~s}^{-1}\right)$ & $a(\mathrm{~nm})$ & $\left(A_{\mathrm{c}} m_{\mathrm{r}} m_{\mathrm{l}} k_{\mathrm{f}}\right)^{0}\left(\mathrm{~s}^{-1}\right)$ & $\alpha_{m}\left(\times 10^{3} s^{-1}\right)$ & $\chi^{2}$ \\
\hline \multicolumn{6}{|c|}{$\alpha_{\mathrm{L}} \beta_{2^{-}}$and $\alpha_{\mathrm{M}} \beta_{2^{-}}$-dependent (8 cases) } \\
\hline Global fitting & 0.40 & 0.109 & 2.82 & $0.00^{\mathrm{a}}$ & 294.1 \\
\hline Individual fitting & $0.32 \pm 0.05^{\mathrm{b}}$ & $0.109^{c}$ & $2.91 \pm 0.57^{\mathrm{b}}$ & $1.03 \pm 0.57^{b}$ & $1.03 \pm 0.57^{\mathrm{b}}$ \\
\hline \multicolumn{6}{|c|}{$\alpha_{\mathrm{M}} \beta_{2}$-Dependent in the presence of anti- $\alpha_{\mathrm{L}} \beta_{2} \mathrm{mAb}$ R3.1 Fab (2 cases) } \\
\hline Global fitting & 0.23 & 0.070 & 1.38 & $0.00^{\mathrm{a}}$ & 0.80 \\
\hline Individual fitting & $0.19 \pm 0.00^{b}$ & $0.070^{\mathrm{C}}$ & $1.25 \pm 0.05^{\mathrm{b}}$ & $0.40 \pm 0.40^{\mathrm{b}}$ & $0.40 \pm 0.40^{\mathrm{b}}$ \\
\hline \multicolumn{6}{|c|}{$\alpha_{\mathrm{L}} \beta_{2}$-Dependent in the presence of anti- $\alpha_{\mathrm{M}} \beta_{2}$ mAb h60.1 Fab (2 cases) } \\
\hline Global fitting & 0.29 & 0.072 & 1.52 & 1.51 & 1.22 \\
\hline Individual fitting & $0.26 \pm 0.02^{\mathrm{b}}$ & $0.072^{\mathrm{c}}$ & $1.41 \pm 0.05^{\mathrm{b}}$ & $1.63 \pm 0.59^{b}$ & $1.63 \pm 0.59^{b}$ \\
\hline
\end{tabular}

${ }^{\mathrm{a}}$ The value was preset to zero.

${ }^{\mathrm{b}}$ The error is the standard error (SE).

${ }^{\mathrm{c}}$ Preset interaction range a obtained from global fitting.

aggregation in the initial phase and decays quickly while $\alpha_{\mathrm{M}} \beta_{2}$-integrin remains functional spanning over entire duration of $120 \mathrm{~s}^{31}$ Noting that, the shear duration of $180 \mathrm{~s}$ in the measurements ${ }^{31}$ was not long enough to present the entire decay phase of aggregation percentage as compared to those measurements with the shear duration of $300 \mathrm{~s},{ }^{24}$ it would be expected that the decay factor for $\beta_{2}$-integrin-dependent aggregation obtained from PMN-E3 aggregation are slightly smaller than that obtained from PMN-WM9 aggrega$\operatorname{tion}^{24}\left(\alpha_{\mathrm{m}}=(1.03 \pm 0.57) \times 10^{-3}\right.$ vs. $(1.29 \pm 0.22) \times$ $10^{-3} \mathrm{~s}^{-1}$ for $1 \mu \mathrm{M}$ fMLP stimulated PMNs).

\section{Correlation Between Molecular and Cellular Decay Factor}

Upon chemotactic stimulation, the expression and binding affinity of $\beta_{2}$-integrin on PMNs are up-regulated within seconds. ${ }^{41}$ Noting that rapid activation of $\alpha_{\mathrm{L}} \beta_{2}$ is transient and reversible within $30 \mathrm{~s}$ while active conformation and high expression of $\alpha_{\mathrm{M}} \beta_{2}$ are stable beyond $10 \mathrm{~min},{ }^{41}$ the decay factor defined above provides a measure of transient decrease in cell adhesion after stimulation. To further determine the biological significance of decay factor, we compared the factor at molecular level $\left(\alpha_{\mathrm{m}}\right)$ with that at cellular level $\left(\alpha_{\mathrm{c}}\right)$. Experimentally, $\alpha_{c}$ was determined by measuring the PMN-E3 aggregation dynamics with PMNs activated by $1 \mu \mathrm{M}$ fMLP for $0,30,120$, and $300 \mathrm{~s}$ before shear was applied. ${ }^{33}$ Time course of the adhesion efficiency $(E)$, estimated from number of collisions resulting in adhesion divided by total number of collisions, was fitted by Eq. (13) and the decay factor $\alpha_{c}$ for $\beta_{2}$-integrin-dependent adhesion was predicted to be $\sim 7.00 \times 10^{-3} \mathrm{~s}^{-1}$. $^{31}$

We first conducted individual fitting for each aggregation curve to obtain three best-fit parameters $\left[k_{\mathrm{r}}^{0},\left(A_{\mathrm{c}} m_{\mathrm{r}} m_{\mathrm{l}} k_{\mathrm{f}}\right)^{0}\right.$, and $\left.\alpha_{\mathrm{m}}\right]$ (Fig. 6a), as summarized in Table 3. Zero-force reverse rate $k_{\mathrm{r}}^{0}$, even varying
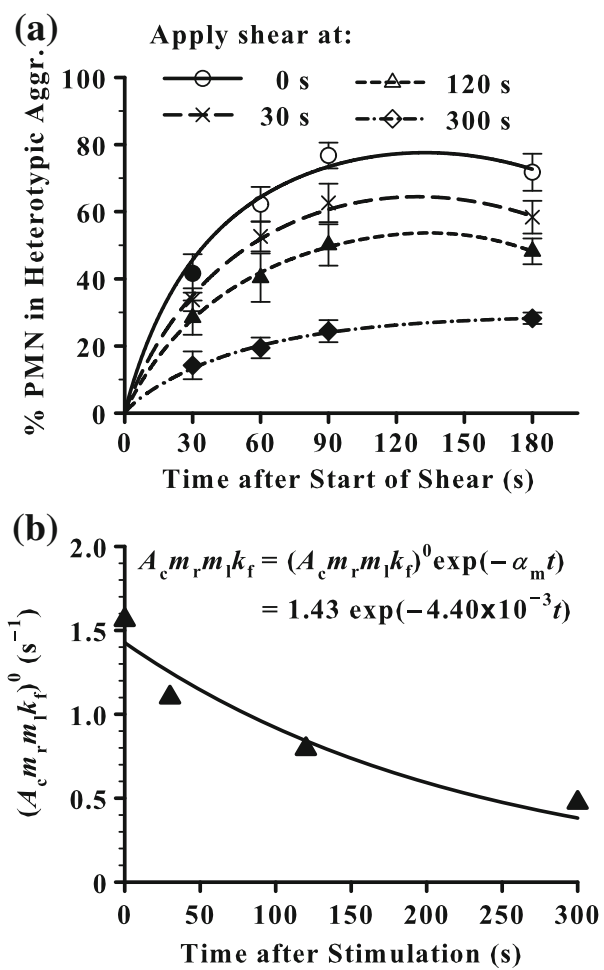

FIGURE 6. Determination of decay factor for $\beta_{2}$-integrinICAM-1 binding in PMN-E3 aggregation from individual fitting. (a) Prediction of shear-induced PMN-E3 aggregation stimulated with $1 \mu \mathrm{M}$ fMLP at fixed time points $(0,30,120$, and $300 \mathrm{~s})$ prior to the application of shear of $200 \mathrm{~s}^{-1}$. (b) Decrease in $\left(A_{\mathrm{c}} m_{\mathrm{r}} m_{1} k_{\mathrm{f}}\right)^{0}$ over time was fitted by an exponential function (Eq. 14). Data (points) were adopted from the literature. ${ }^{31}$

slightly $\left(0.05-0.14 \mathrm{~s}^{-1}\right)$, was found to be comparable to those in the literatures, ${ }^{11,24,26}$ while the effective forward rate $\left(A_{\mathrm{c}} m_{\mathrm{r}} m_{\mathrm{l}} k_{\mathrm{f}}\right)^{0}$ decreases over time. Here we applied two strategies to determine the decay factor $\alpha_{\mathrm{m}}$ at molecular level. One was to average all the values of $\alpha_{\mathrm{m}}$ in each group summarized in Table 3 to obtain the mean \pm standard error $\left((3.94 \pm 1.63) \times 10^{-3} \mathrm{~s}^{-1}\right)$. The other was to fit the values of $\left(A_{\mathrm{c}} m_{\mathrm{r}} m_{\mathrm{l}} k_{\mathrm{f}}\right)^{0}$ at 0,30 , 
TABLE 3. Kinetic parameters of time-dependent $\beta_{2}$-integrin and ICAM-1 binding.

\begin{tabular}{llllll}
\hline Duration $(\mathrm{s})$ & $k_{\mathrm{r}}^{0}\left(\mathrm{~s}^{-1}\right)$ & $a(\mathrm{~nm})$ & $\left(A_{\mathrm{c}} m_{\mathrm{r}} m_{\mathrm{l}} k_{\mathrm{f}}\right)^{0}\left(\mathrm{~s}^{-1}\right)$ & $\alpha_{\mathrm{m}}\left(\times 10^{3} \mathrm{~s}^{-1}\right)$ & $\chi^{2}$ \\
\hline 0 & 0.14 & $0.109^{\mathrm{a}}$ & 1.56 & 3.80 & 1.45 \\
30 & 0.11 & $0.109^{\mathrm{a}}$ & 1.10 & 3.96 & 0.30 \\
120 & 0.05 & $0.109^{\mathrm{a}}$ & 0.79 & 8.00 & 0.06 \\
300 & 0.11 & $0.109^{\mathrm{a}}$ & 0.47 & 0.02 & 0.11 \\
Mean $\pm \mathrm{SE}$ & $0.10 \pm 0.02$ & $0.109^{\mathrm{a}}$ & $0.98 \pm 0.23$ & $3.94 \pm 1.63$ & $0.48 \pm 0.33$ \\
\hline
\end{tabular}

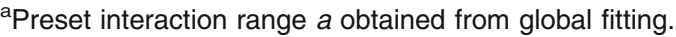

120, and $300 \mathrm{~s}$ to Eq. (14) to estimate the decay factor of $(4.40 \pm 1.21) \times 10^{-3} \mathrm{~s}^{-1}$ (Fig. 6b). The two values obtained were in excellent agreement, which further confirmed the validity of the current model. More importantly, they were well comparable to that at cellular level $\left(\alpha_{\mathrm{c}}=7.00 \times 10^{-3} \mathrm{~s}^{-1}\right),{ }^{31}$ suggesting that the decay of cell aggregation percentage induced by chemotactic stimulation was presumably attributed to the reduction of forward rate of $\beta_{2}$-integrin-ICAM- 1 interactions that mediates the cell aggregation.

\section{DISCUSSION}

In aforementioned descriptions, we developed, validated, and applied the current model to two distinct types of measurements: (1) homotypic vs. heterotypic aggregation; (2) latex beads vs. cells; (3) protein-protein (protein $\mathrm{G}-\mathrm{IgG}$ ) vs. protein-carbohydrate bond $\left(\beta_{2}\right.$-integrin-ICAM-1); and (4) varied vs. steady shear history. These results indicated that the model is reliable and applicable in various shear-induced cell/bead aggregation dynamics. Here we discussed two more important points of the model.

\section{Re-Analysis of Existing Data Using New Model}

We previously developed a model to predict the shear-induced 2D kinetics of PMN-WM9 melanoma cell aggregation by adding the newly-formed doublets into the doublet pool and transferring the singlets dissociated from existing doublets into the singlet pool. ${ }^{24}$ This is equivalent to a transient probability from zero-bond to one-bond of $f_{\mathrm{c} 0} \varepsilon$, which is $f_{\mathrm{c}} \varepsilon$ $\left(=f_{\mathrm{c} 0} \varepsilon p_{0}\right.$, if $\left.C_{10}=C_{20}\right)$ in the current model. In other words, the previous model did not count in the decrease of cell concentration due to doublet formation. ${ }^{24}$ To test this, numerical calculations were performed using the current model for PMN-WM9 cell aggregation at $G=100 \mathrm{~s}^{-1}$ and $\eta=1 \mathrm{cP}$ with kinetic parameters of $k_{\mathrm{r}}^{0}=0.6 \mathrm{~s}^{-1}, a=0.04 \mathrm{~nm}, \alpha_{\mathrm{m}}=1.0 \times$ $10^{-3} \mathrm{~s}^{-1}$ and a variable of $\left(A_{\mathrm{c}} m_{\mathrm{r}} m_{\mathrm{l}} k_{\mathrm{f}}\right)^{0}$. As shown in Fig. 7, neglecting $p_{0}$ term in the previous $\operatorname{model}^{24}$ has little effect on low aggregation percentage $\left(p_{0} \sim p_{0}^{2}\right)$ but results in significant difference at high percentage

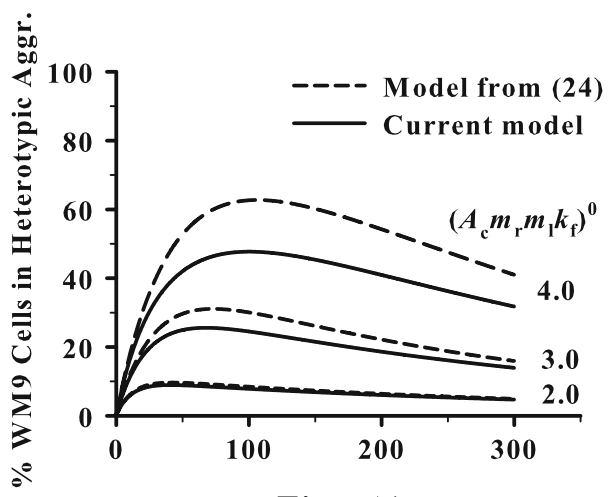

Time (s)

FIGURE 7. Parametric dependence of PMN-WM9 aggregation dynamics at varied $\left(A_{\mathrm{c}} m_{\mathrm{r}} m_{1} k_{\mathrm{f}}\right)^{0}=2.0,3.0$, and $4.0 \mathrm{~s}^{-1}$. Numerical calculations were compared between the current model (solid lines) and the previous model ${ }^{24}$ (dashed lines) with a parameter set of $k_{r}^{0}=0.6 \mathrm{~s}^{-1}, a=0.04 \mathrm{~nm}, \alpha_{\mathrm{m}}=1.0 \times$ $10^{-3} \mathrm{~s}^{-1}$ at a shear rate of $100 \mathrm{~s}^{-1}$ and a medium viscosity of $1.0 \mathrm{cP}$.

$\left(p_{0} \gg p_{0}^{2}\right)$. Noting that the percentage of tumor cells in heterotypic aggregation was lower than $40 \%,{ }^{24}$ the kinetic parameters best-fitted from the current and previous models appeared to have no significant difference (data not shown). It should be pointed out that at high aggregation percentage, i.e., $\sim 80 \%$ between fMLP-stimulated PMNs with TNF- $\alpha$-stimulated WM9 cells, the differences of estimated parameters especially for effective forward rate $\left(A_{\mathrm{c}} m_{\mathrm{r}} m_{\mathrm{l}} k_{\mathrm{f}}\right)^{0}$ from the two models are no longer negligible.

\section{Capture Efficiency Upon Two-Body Collision}

In the current model, capture efficiency of two-body collision was simplified by $\varepsilon \approx A_{\mathrm{c}} m_{\mathrm{r}} m_{\mathrm{l}} k_{\mathrm{f}} \bar{\tau}$ for all abovepresented calculations. To test the model, numerical calculations were conducted without any simplifications for the probability distribution of bonds $\left\{p_{\mathrm{c} 0}\right.$, $\left.p_{\mathrm{c} 1}, \ldots, p_{\mathrm{c} n}, \ldots, p_{\mathrm{c} N}\right\}$ to get the exact value of capture efficiency by $\varepsilon=1-p_{\mathrm{c} 0}$ (Eq. 7). Two sets of parameters were applied for the above calculations: $k_{\mathrm{r}}^{0}=$ $1.0 \times 10^{-2} \mathrm{~s}^{-1}, a=0.3 \mathrm{~nm}$, and $A_{\mathrm{c}} m_{\mathrm{r}} m_{\mathrm{l}} k_{\mathrm{f}}=5.0 \times$ $10^{-2} \mathrm{~s}^{-1}$ for protein-protein bonds in homotypic cell aggregation (Fig. 8a) and $k_{\mathrm{r}}^{0}=0.6 \mathrm{~s}^{-1}, a=0.04 \mathrm{~nm}$, 

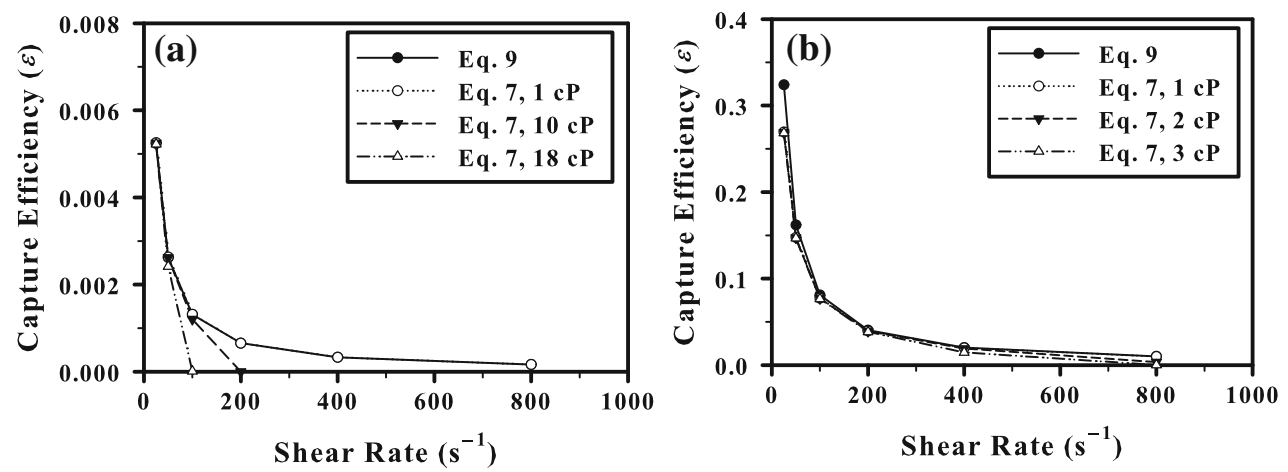

FIGURE 8. Capture efficiency upon two-body collision $(\varepsilon)$ obtained from direct numerical calculation (Eq. 7) with systematically varied shear rates and medium viscosity was compared to the simplified one (Eq. 9). Two sets of parameters were used: (a) $k_{\mathrm{r}}^{0}=1.0 \times 10^{-2} \mathrm{~s}^{-1}, a=0.3 \mathrm{~nm}$, and $A_{\mathrm{c}} m_{\mathrm{r}} m_{1} k_{\mathrm{f}}=5.0 \times 10^{-2} \mathrm{~s}^{-1}$ for protein-protein bonds in homotypic aggregation of latex beads ${ }^{21}$ and (b) $k_{\mathrm{r}}^{0}=0.6 \mathrm{~s}^{-1}, a=0.04 \mathrm{~nm}$, and $A_{\mathrm{c}} m_{\mathrm{r}} m_{\mathrm{l}} k_{\mathrm{f}}=3.0 \mathrm{~s}^{-1}$ for protein-carbohydrate interactions in heterotypic aggregation of PMN-WM9 cells. ${ }^{24}$ Simplified solutions (solid lines) were superimposed with the numerical calculations completely at $1 \mathrm{cP}$ in (a) and partially at $1 \mathrm{cP}$ when $\mathrm{G}>100 \mathrm{~s}^{-1}$ in (b) (dotted line).

and $A_{\mathrm{c}} m_{\mathrm{r}} m_{\mathrm{l}} k_{\mathrm{f}}=3.0 \mathrm{~s}^{-1}$ for protein-carbohydrate interactions in heterotypic aggregation (Fig. 8b). As shown in Fig. 8, the simplification was quite reasonable at various shear rates $\left(G<100 \mathrm{~s}^{-1}\right.$ in Fig. 8 a or $50 \mathrm{~s}^{-1}<G<400 \mathrm{~s}^{-1}$ in Fig. 8b). The values of $p_{\mathrm{cn}}$ also proved that the doublets are most likely linked by only one bond because $p_{\mathrm{c} 2}$ is at least one orderof-magnitude smaller than $p_{\mathrm{c} 1}$ (data not shown). By contrast, $p_{\mathrm{c} n}$ was significantly lower than the simplified values under high shear rate and high viscosity, implying that the impact of applied force on $k_{\mathrm{r}}$ could not be neglected. This is because, once a bond is formed, bond dissociation would not likely happen within a short collision duration when $k_{\mathrm{r}}$ is low. But bond rupture should be accounted to reduce the capture efficiency when $k_{\mathrm{r}}$ is high enough. Furthermore, it was found that the simplification in Eq. (9) is no longer applicable at low shear rates $\left(G<50 \mathrm{~s}^{-1}\right)$ for PMNWM9 case (Fig. 8b), presumably due to the high $A_{\mathrm{c}} m_{\mathrm{r}} m_{\mathrm{l}} k_{\mathrm{f}}$ value and long contact duration. In those cases, only the numerical calculations of two-body collision should be applied.

In this paper, we developed a new model upon a probabilistic model of small system kinetics and twobody collision theorem. As a universal framework, it enables one to quantify the cell/bead aggregation dynamics in doublet aggregates and to predict the binding kinetics of interacting molecular pair that mediates cell/bead aggregation by fitting measured data to the model. We also demonstrated that neglecting of two singlets separation in a previous model would overestimate the bead aggregation. Together with the chemotactic stimulations, it is also applicable to address such the biological issues as how the chemoattractant-induced regulation of molecular expressions and conformations.

\section{ACKNOWLEDGMENTS}

This work was supported by National Natural Science Foundation of China grants 30730032, 11072251, 10902117, and 10702075, Chinese Academy of Sciences grants KJCX2-YW-L08 and Y2010030, and National Key Basic Research Foundation of China grant 2011 CB710904.

\section{REFERENCES}

${ }^{1}$ Adler, P. M. Interaction of unequal spheres. 1. Hydrodynamic interaction - colloidal forces. J. Colloid Interf. Sci. 84(2):461-474, 1981.

${ }^{2}$ Bartok, W., and S. G. Mason. Particle motions in sheared suspensions V. Rigid rods and collision doublets of spheres. J. Colloid Interf. Sci. 12(3):243-262, 1957.

${ }^{3}$ Bell, G. I. Models for specific adhesion of cells to cells. Science 200(4342):618-627, 1978.

${ }^{4}$ Capo, C., F. Garrouste, A. M. Benoliel, P. Bongrand, A. Ryter, and G. I. Bell. Concanavalin-A-mediated thymocyte agglutination - a model for a quantitative study of cell-adhesion. J. Cell Sci. 56(1):21-48, 1982.

${ }^{5}$ Chesla, S. E., P. Selvaraj, and C. Zhu. Measuring twodimensional receptor-ligand binding kinetics by micropipette. Biophys. J. 75(3):1553-1572, 1998.

${ }^{6}$ Coussens, L. M., and Z. Werb. Inflammation and cancer. Nature 420(6917):860-867, 2002.

${ }^{7}$ Cozens-Roberts, C., D. A. Lauffenburger, and J. A. Quinn. Receptor-mediated cell attachment and detachment kinetics. 1. Probabilistic model and analysis. Biophys. J. 58(4):841-856, 1990

${ }^{8}$ Gachet, C. Regulation of platelet functions by $\mathrm{P} 2$ receptors. Annu. Rev. Pharmacol. Toxicol. 46:277-300, 2006.

${ }^{9}$ Goldsmith, H. L., T. A. Quinn, G. Drury, C. Spanos, F. A. McIntosh, and S. I. Simon. Dynamics of neutrophil aggregation in Couette flow revealed by videomicroscopy: effect of shear rate on two-body collision efficiency and doublet lifetime. Biophys. J. 81(4):2020-2034, 2001. 
${ }^{10}$ Hentzen, E. R., S. Neelamegham, G. S. Kansas, J. A. Benanti, L. V. McIntire, C. W. Smith, and S. I. Simon. Sequential binding of CD11a/CD18 and CD11b/CD18 defines neutrophil capture and stable adhesion to Intercellular adhesion molecule-1. Blood 95(3):911-920, 2000.

${ }^{11}$ Hoskins, M. H., and C. Dong. Kinetics analysis of binding between melanoma cells and neutrophils. Mol. Cell. Biomech. 3(2):79-87, 2006.

${ }^{12}$ Huang, P. Y., and J. D. Hellums. Aggregation and disaggregation kinetics of human blood-platelets. 1. Development and validation of a population balance method. Biophys. J. 65(1):334-343, 1993.

${ }^{13}$ Huang, P. Y., and J. D. Hellums. Aggregation and disaggregation kinetics of human blood-platelets. 2. Shearinduced platelet-aggregation. Biophys. J. 65(1):344-353, 1993.

${ }^{14}$ Huang, P. Y., and J. D. Hellums. Aggregation and disaggregation kinetics of human blood-platelets. 3. The disaggregation under shear-stress of platelet aggregates. Biophys. J. 65(1):354-361, 1993.

${ }^{15}$ Huh, S. J., S. Liang, A. Sharma, C. Dong, and G. P. Robertson. Transiently entrapped circulating tumor cells interact with neutrophils to facilitate lung metastasis development. Cancer Res. 70(14):6071-6082, 2010.

${ }^{16} \mathrm{Im}$, J. H., W. L. Fu, H. Wang, S. K. Bhatia, D. A. Hammer, M. A. Kowalska, and R. J. Muschel. Coagulation facilitates tumor cell spreading in the pulmonary vasculature during early metastatic colony formation. Cancer Res. 64(23):8613-8619, 2004.

${ }^{17}$ Jadhav, S., B. S. Bochner, and K. Konstantopoulos. Hydrodynamic shear regulates the kinetics and receptor specificity of polymorphonuclear leukocyte-colon carcinoma cell adhesive interactions. J. Immunol. 167(10):59865993, 2001.

${ }^{18}$ Jadhav, S., and K. Konstantopoulos. Fluid shear- and time-dependent modulation of molecular interactions between PMNs and colon carcinomas. Am. J. Physiol. Cell Physiol. 283(4):C1133-C1143, 2002.

${ }^{19}$ Konstantopoulos, K., S. Kukreti, and L. V. McIntire. Biomechanics of cell interactions in shear fields. Adv. Drug Deliv. Rev. 33(1-2):141-164, 1998.

${ }^{20}$ Kroll, M. H., J. D. Hellums, L. V. McIntire, A. I. Schafer, and J. L. Moake. Platelets and shear stress. Blood 88(5):1525-1541, 1996.

${ }^{21}$ Kwong, D., D. F. J. Tees, and H. L. Goldsmith. Kinetics and locus of failure of receptor-ligand-mediated adhesion between latex spheres. 2. Protein-protein bond. Biophys. J. 71(2):1115-1122, 1996.

${ }^{22}$ Laurenzi, I. J., and S. L. Diamond. Monte Carlo simulation of the heterotypic aggregation kinetics of platelets and neutrophils. Biophys. J. 77(3):1733-1746, 1999.

${ }^{23}$ Liang, S., M. J. Slattery, and C. Dong. Shear stress and shear rate differentially affect the multi-step process of leukocyte-facilitated melanoma adhesion. Exp. Cell Res. 310(2):282-292, 2005.

${ }^{24}$ Liang, S. L., C. L. Fu, D. Wagner, H. G. Guo, D. Y. Zhan, C. Dong, and M. Long. Two-dimensional kinetics of beta(2)-integrin and ICAM-1 bindings between neutrophils and melanoma cells in a shear flow. Am. J. Physiol. Cell Physiol. 294:C743-C753, 2008.

${ }^{25}$ Liang, S. L., A. Sharma, H. H. Peng, G. Robertson, and C. Dong. Targeting mutant (V600E) B-Raf in melanoma interrupts immunoediting of leukocyte functions and melanoma extravasation. Cancer Res. 67(12):5814-5820, 2007.
${ }^{26}$ Lomakina, E. B., and R. E. Waugh. Micromechanical tests of adhesion dynamics between neutrophils and immobilized ICAM-1. Biophys. J. 86(2):1223-1233, 2004.

${ }^{27}$ Long, M., H. L. Goldsmith, D. F. J. Tees, and C. Zhu. Probabilistic modeling of shear-induced formation and breakage of doublets cross-linked by receptor-ligand bonds. Biophys. J. 76(2):1112-1128, 1999.

${ }^{28}$ McCarty, O. J. T., S. Jadhav, M. M. Burdick, W. R. Bell, and K. Konstantopoulos. Fluid shear regulates the kinetics and molecular mechanisms of activation-dependent platelet binding to colon carcinoma cells. Biophys. J. 83(2):836-848, 2002.

${ }^{29}$ McQuarrie, D. A. Kinetics of small systems. I. J. Chem. Phys. 38(2):433-436, 1963.

${ }^{30}$ Merkel, R. Force spectroscopy on single passive biomolecules and single biomolecular bonds. Phys. Rep. 346(5): 344-385, 2001.

${ }^{31}$ Neelamegham, S., A. D. Taylor, A. R. Burns, C. W. Smith, and S. I. Simon. Hydrodynamic shear shows distinct roles for LFA-1 and Mac-1 in neutrophil adhesion to intercellular adhesion molecule-1. Blood 92(2):1626-1638, 1998.

${ }^{32}$ Neelamegham, S., A. D. Taylor, J. D. Hellums, M. Dembo, C. W. Smith, and S. I. Simon. Modeling the reversible kinetics of neutrophil aggregation under hydrodynamic shear. Biophys. J. 72(4):1527-1540, 1997.

${ }^{33}$ Neelamegham, S., A. D. Taylor, H. Shankaran, C. W. Smith, and S. I. Simon. Shear and time-dependent changes in Mac-1, LFA-1, and ICAM-3 binding regulate neutrophil homotypic adhesion. J. Immunol. 164(7):3798-3805, 2000.

${ }^{34}$ Neumann, F. J., N. Marx, M. Gawaz, K. Brand, I. Ott, C. Rokitta, C. Sticherling, C. Meinl, A. May, and A. Schomig. Induction of cytokine expression in leukocytes by binding of thrombin-stimulated platelets. Circulation 95(10):2387-2394, 1997.

${ }^{35}$ Ott, I., F. J. Neumann, M. Gawaz, M. Schmitt, and A. Schomig. Increased neutrophil-platelet adhesion in patients with unstable angina. Circulation 94(6):1239-1246, 1996.

${ }^{36}$ Palabrica, T., R. Lobb, B. C. Furie, M. Aronovitz, C. Benjamin, Y. M. Hsu, S. A. Sajer, and B. Furie. Leukocyte accumulation promoting fibrin deposition is mediated invivo by P-selectin on adherent platelets. Nature 359(6398):848-851, 1992.

${ }^{37}$ Press, W. H., B. P. Flannery, S. A. Teukolsky, and W. T. Vetterling. Numerical Recipes in Fortran 77: The Art of Scientific Computing (2nd ed.). Cambridge: Cambridge University Press, pp. 675-683, 1992.

${ }^{38}$ Sahai, E. Illuminating the metastatic process. Nat. Rev. Cancer 7(10):737-749, 2007.

${ }^{39}$ Shankaran, H., and S. Neelamegham. Hydrodynamic forces applied on intercellular bonds, soluble molecules, and cell-surface receptors. Biophys. J. 86(1):576-588, 2004.

${ }^{40}$ Simon, S. I., J. D. Chambers, and L. A. Sklar. Flow cytometric analysis and modeling of cell-cell adhesive interactions - the neutrophil as a model. J. Cell Biol. 111(6): 2747-2756, 1990.

${ }^{41}$ Simon, S. I., and C. E. Green. Molecular mechanics and dynamics of leukocyte recruitment during inflammation. Annu. Rev. Biomed. Eng. 7:151-185, 2005.

${ }^{42}$ Simson, D. A., M. Strigl, M. Hohenadl, and R. Merkel. Statistical breakage of single protein A-IgG bonds reveals crossover from spontaneous to force-induced bond dissociation. Phys. Rev. Lett. 83(3):652-655, 1999.

${ }^{43}$ Slattery, M. J., S. Liang, and C. Dong. Distinct role of hydrodynamic shear in leukocyte-facilitated tumor cell extravasation. Am. J. Physiol. Cell Physiol. 288(4):C831C839, 2005. 
${ }^{44}$ Smoluchowski, M. V. Versuch einer mathematischen Theorie der Koagulationskinetik kolloider Losungen. Z. Phys. Chem. 92:129-168, 1917.

${ }^{45}$ Tandon, P., and S. L. Diamond. Hydrodynamic effects and receptor interactions of platelets and their aggregates in linear shear flow. Biophys. J. 73(5):2819-2835, 1997.

${ }^{46}$ Tandon, P., and S. L. Diamond. Kinetics of beta(2)-integrin and L-selectin bonding during neutrophil aggregation in shear flow. Biophys. J. 75(6):3163-3178, 1998.

${ }^{47}$ Taylor, A. D., S. Neelamegham, J. D. Hellums, C. W. Smith, and S. I. Simon. Molecular dynamics of the transition from L-selectin- to beta(2)-integrin-dependent neutrophil adhesion under defined hydrodynamic shear. Biophys. J. 71(6):3488-3500, 1996.

${ }^{48}$ Tees, D. F. J., O. Coenen, and H. L. Goldsmith. Interaction forces between red-cells agglutinated by antibody. 4. Time and force dependence of break-up. Biophys. J. 65(3):1318-1334, 1993.

${ }^{49}$ Tees, D. F. J., and H. L. Goldsmith. Kinetics and locus of failure of receptor-ligand-mediated adhesion between latex spheres. 1. Protein-carbohydrate bond. Biophys. J. 71(2): 1102-1114, 1996.

${ }^{50}$ van de Ven, T. G. M., and S. G. Mason. Microrheology of colloidal dispersions. 4. Pairs of interacting spheres in shear-flow. J. Colloid Interf. Sci. 57(3):505-516, 1976.

${ }^{51}$ Zhang, P., T. Ozdemir, C. Y. Chung, G. P. Robertson, and C. Dong. Sequential binding of alphaVbeta3 and ICAM-1 determines fibrin-mediated melanoma capture and stable adhesion to $\mathrm{CD} 11 \mathrm{~b} / \mathrm{CD} 18$ on neutrophils. J. Immunol. 186(1):242-254, 2011.

${ }^{52} \mathrm{Zhu}, \mathrm{C}$. Kinetics and mechanics of cell adhesion. J. Biomech. 33(1):23-33, 2000.

${ }^{53}$ Zhu, C., M. Long, S. E. Chesla, and P. Bongrand. Measuring receptor/ligand interaction at the single-bond level: Experimental and interpretative issues. Ann. Biomed. Eng. 30(3):305-314, 2002.

${ }^{54}$ Zwartz, G., A. Chigaev, T. Foutz, R. S. Larson, R. Posner, and L. A. Sklar. Relationship between molecular and cellular dissociation rates for VLA-4/VCAM-1 interaction in the absence of shear stress. Biophys. J. 86(2):1243-1252, 2004. 